\title{
Progress in Nanocarriers Codelivery System to Enhance the Anticancer Effect of Photodynamic Therapy
}

\author{
Yu-Ling Yang ${ }^{\dagger}, \mathrm{Ke} \mathrm{Lin}^{\dagger}$ and Li Yang * \\ State Key Laboratory of Biotherapy and Cancer Center/Collaborative Innovation Center for Biotherapy, \\ West China Hospital, Sichuan University, Chengdu 610041, China; yyuling@stu.scu.edu.cn (Y.-L.Y.); \\ linke@stu.scu.edu.cn (K.L.) \\ * Correspondence: yl.tracy73@scu.edu.cn \\ + YuLing Yang and Ke Lin contributed equally to the manuscript.
}

check for updates

Citation: Yang, Y.-L.; Lin, K.; Yang, L. Progress in Nanocarriers Codelivery System to Enhance the Anticancer Effect of Photodynamic Therapy. Pharmaceutics 2021, 13, 1951. https: / / doi.org/10.3390/ pharmaceutics13111951

Academic Editors: Yvonne Perrie, Marina Santiago Franco and Yu Seok Youn

Received: 7 October 2021

Accepted: 12 November 2021

Published: 18 November 2021

Publisher's Note: MDPI stays neutral with regard to jurisdictional claims in published maps and institutional affiliations.

Copyright: (C) 2021 by the authors Licensee MDPI, Basel, Switzerland. This article is an open access article distributed under the terms and conditions of the Creative Commons Attribution (CC BY) license (https:/ / creativecommons.org/licenses/by/ $4.0 /)$.

\begin{abstract}
Photodynamic therapy (PDT) is a promising anticancer noninvasive method and has great potential for clinical applications. Unfortunately, PDT still has many limitations, such as metastatic tumor at unknown sites, inadequate light delivery and a lack of sufficient oxygen. Recent studies have demonstrated that photodynamic therapy in combination with other therapies can enhance anticancer effects. The development of new nanomaterials provides a platform for the codelivery of two or more therapeutic drugs, which is a promising cancer treatment method. The use of multifunctional nanocarriers for the codelivery of two or more drugs can improve physical and chemical properties, increase tumor site aggregation, and enhance the antitumor effect through synergistic actions, which is worthy of further study. This review focuses on the latest research progress on the synergistic enhancement of PDT by simultaneous multidrug administration using codelivery nanocarriers. We introduce the design of codelivery nanocarriers and discuss the mechanism of PDT combined with other antitumor methods. The combination of PDT and chemotherapy, gene therapy, immunotherapy, photothermal therapy, hyperthermia, radiotherapy, sonodynamic therapy and even multidrug therapy are discussed to provide a comprehensive understanding.
\end{abstract}

Keywords: codelivery nanocarriers; photodynamic therapy; anticancer therapies; combination therapy

\section{Introduction of Photodynamic Therapy and Photosensitizers \\ 1.1. Photodynamic Therapy}

Photodynamic therapy (PDT) is a modern noninvasive antitumor technique that has great clinical application potential due to its advantages of simple operation and low systemic toxicity. PDT has been clinically approved for the treatment of some tumors, such as advanced esophageal cancer and advanced lung cancer [1]. Local or systemic photosensitizers (PSs) can be activated to produce cytotoxic reactive oxygen species (ROS) after absorbing light from an appropriate wavelength laser, which can induce tumor cell necrosis and apoptosis or cause angiotoxicity to block tumor cell nutrient supply. In addition, acute inflammatory responses and immunogenic cell death (ICD) induced by PDT have been shown to activate the body's immune system and result in the reconstruction of the tumor microenvironment $[2,3]$.

There are two main mechanisms of the photodynamic reaction. When PSs enter cells, light at a wavelength coinciding with the PS absorption spectrum irradiates the issue, and PSs will be converted from the singlet basic energy state into the excited singlet state because of photon absorption. Part of the energy directs a PS molecule to the excited triplet state. In type I reactions, the PSs in their excited triplet state react with biomolecules and ROS can be generated from radical oxygen species formed by electron transfer reactions such as superoxide ions $\left(\mathrm{O}_{2}{ }^{-}\right)$and hydroxyl radical $\left(\mathrm{OH}^{\bullet}\right)$. In type II reactions, the energy of PSs in their excited triplet state is transferred directly to the oxygen molecule in the basic energetic state, resulting in the generation of singlet oxygen, which is highly 
reactive and cytotoxic [2,4]. ROS produced by the two reactions irreversibly damage cells and microvessels, and ROS can fight against cancer by inducing apoptotic cell death, a subroutine mode of active immunity [3,5]. Type II is considered as the most important process affecting PDT efficiency. The balance of the contribution of both reactions depends on many factors, including oxygen concentration and on the structural features of the PSs.

\subsection{Photosensitizers}

PDT emerged as a tumor treatment in 1907, and the early progression of it is closely related to the development of PSs [4]. The PS types are generally divided into non-porphyrins and porphyrins. The typical non-porphyrin PSs are hypericin, including phenothiazinium dyes, xanthene dyes, phthalimide derivatives, indocyanine green (ICG) etc. Methylene blue (MB), toluidine blue $\mathrm{O}$, Rose Bengal (RB), ICG, as well as the near-infrared dye IR780-iodide have commonly been used in recent years [6-8]. In addition, inorganic materials like graphene oxide (GO) and gold/silver nanoparticles (AuNPs/AgNPs) are also included [9-11], the latter have good biocompatibility and tunable optical properties, and ${ }^{1} \mathrm{O}_{2}$ can be generated through surface plasmon excitation for PDT of tumors [12]. Metal oxides such as $\mathrm{TiO}_{2}$ and $\mathrm{ZnO}_{2}$ NPs can be photoactivated to produce ROS through electronhole pair interactions with the surrounding ${ }^{1} \mathrm{O}_{2}$. These nanomaterials generally have the advantages of low toxicity, inertness, good biocompatibility and photostability [13]. Other materials, including black phosphorus nanosheets [14], fullerene [15] and GCNS [16], can also be modified to achieve multifunctionalization.

Porphyrins PSs in the early stage were mainly mixtures obtained from natural porphyrins. For example, hematoporphyrin derivative (HPD), was first used as a PS for bladder cancer in 1970 [17,18]. Unfortunately, Since such PSs had a long half-life and would accumulate excessively in the skin, patients receiving the treatment need to avoid intense light for weeks and their lifestyle is severely affected $[19,20]$. The second generation are substances with a pure structure, including porphyrins, chlorins, benzoporphyrins and phthalocyanines $[9,10]$. The common one is 5 -aminolevulinic acid (5-ALA), a prodrug of protoporphyrin IX (PpIX), also the current FDA-approved standard for brain tumor visualization. Chlorin e6 (Ce6) is photoactivated at near-infrared wavelengths (664-665 nm) [21-23], has a high efficiency of singlet oxygen generation, and can penetrate deep tissue [24]. Visudyne, the active ingredient of which is verteporfin (benzoporphyrin derivative, BPD), is the only FDA-approved NIR PS for intravenous injection with high singlet oxygen yield and a low skin phototoxicity [25]. Verteporfin has poor solubility and rapid clearance speed in vivo [26], so nanocarriers (liposomes) or cosolvents are used to ameliorate these limitations [27]. Phthalocyanines have two main UV-vis absorption wavelengths: $350 \mathrm{~nm}$ and $680 \mathrm{~nm}$, whose high intensity is one of the main characteristics of these dyes. Due to the presence of a high $Q$ band at $680 \mathrm{~nm}$, these dyes can be activated by red light with strong tissue penetration [28]. They have low toxicity and rapid elimination properties [29]. The photophysical properties of phthalocyanines are strongly dependent on central metal ions, and complexes with diamagnetic metal ions such as $\mathrm{Zn}^{2+}$ and $\mathrm{Al}^{3+}$ help to enhance PDT, including zinc phthalocyanine $(\mathrm{ZnPc})$, zinc hexadecafluorophthalocyanine $\left(\mathrm{ZnF}_{16} \mathrm{Pc}\right)$, aluminum chloride phthalocyanine (ClAlPc), etc. At present, there have been a variety of phthalocyanine-based PSs in clinical trials, such as CGP55847, Photosens and so on [30]. The third generation of PSs currently under investigation is designed to synthesize substances that have a higher affinity for tumor tissue, in the form of former drugs or those based on novel drug delivery systems (liposome, polymer, or micelle) [17-19].

The way PDT induces cell death (apoptosis, necrosis, autophagy cell death, or a combination of them) is related to the localization of PSs in subcellular components. Many reports indicate that mitochondria are important targets of PDT, and PSs targeting mitochondria has been proved to induce apoptosis more effectively, which may be related to the loss of mitochondrial membrane potential, inhibition of ADP/ATP exchange, respiratory enzymes and oxidative phosphorylation [4,20,31]. PSs targeting lysosomes could induce the release of cathepsins upon photodamage, which could cleave pro-apoptotic protein Bid and pro- 
mote mitochondrial apoptosis, or cleave caspase-3 and inhibit apoptosis [31]. Necrosis is caused by high levels of cell damage and usually requires a higher dose than apoptosis. When PSs is predominantly present in the plasma membrane, this is the main form of cell death. In this type of injury, plasma membrane integrity is lost, cells dissolve, and tissue inflammation is triggered. PDT has been reported to induce autophagy, a mechanism for cell survival or adaptation in which injured cells attempt to repair or remove dysfunctional organelles to promote survival. If the initial response fails, autophagy turns into a cell death signal. PDT-induced autophagy is associated with subcellular sites damaged by ROS and can be triggered by light damage to key organelles such as endoplasmic reticulum, mitochondria and lysosome [32,33].

In addition, the fluorescence capability of PSs is widely used in clinical imaging, especially NIR fluorescence imaging technology, which can depict tumor tissue in real time, thus being used to provide highly sensitive images for surgery or to monitor drug therapy [34].

\section{Nanotechniques to Improve Photodynamic Therapy}

Poor water solubility is a common feature of PSs and limits their clinical application. Chemical coupling combining hydrophobic PS and hydrophilic substances could enhance the circulation time in the blood [24,35]. Physical binding is a more common approach. PSs are loaded into chitosan (CS) [23,36], cationic polymer liposome microcapsules [37-39] and other carriers, which can not only improve the physical and chemical properties but also avoid degradation in the physiological environment [40-42].

The use of targeted vectors helps reduce toxicity and allows the same therapeutic effect to be achieved with smaller doses of PS. This is mainly related to increasing the selectivity of PSs tissue distribution and improving drug bioavailability [4]. In addition to targeting specific tissues, simultaneous targeting of multiple organelles has also been reported to have a stronger therapeutic effect. This can be achieved by combining PSs with different subcellular localization or by using different nanocarriers $[27,43,44]$.

Hypoxia at the treatment site $[45,46]$, low ROS generation efficiency, and low light penetration are also limitations. Inorganic NPs such as AgNPs can mediate greater ROS production through $\mathrm{Ag}^{+}$ions released from the surface and have been reported to enhance the anticancer effect of PSs such as MB and Ce6 [47-49]. GO is also commonly used to enhance ROS production, and studies have found that the use of GO loaded with MB can raise the local tumor temperature to approximately $40{ }^{\circ} \mathrm{C}$, effectively preventing tumor metastasis and regeneration [50]. The use of noncovalently bound graphene oxide dihydrogen porphyrin derivatives as long-wavelength absorbers of PS ( $\lambda_{\max }$ of $\left.707 \mathrm{~nm}\right)$ enables light to penetrate deeper into the tumor site, overcoming the limitations of low light penetration [51]. For some hypoxic tumors, oxygen or oxygen generators can be codelivered with the PS to enhance the PDT effect through a self-supply of oxygen. Common oxygen transport carriers include nanoscale artificial red blood cell tumors targeting human serum albumin, which can deliver oxygen-loaded hemoglobin and PSs to the tumor site $[52,53]$. Perfluorocarbon (PFC), an artificial blood substitute that can dissolve large amounts of oxygen, can also alleviate tumor hypoxia after cotargeted delivery with PS [54]. Another method is to use metal carriers to react with peroxide to generate oxygen at tumor sites $[55,56]$. For example, an activated system using linoleic acid peroxide (LAHP) and iron oxide NPs (IO NPs) can induce the apoptosis of cancer cells through tumor-specific ${ }^{1} \mathrm{O}_{2}$ generation and subsequent ROS-mediated mechanisms [46]. In addition, it is feasible to transform type II oxygen-sensitive photochemical reactions into Type I photochemical reactions [57]. Other approaches to overcome hypoxia include the use of siRNA to inhibit hypoxia-inducible factors.

The upregulation of vascular endothelial growth factor (VEGF) and heat shock protein 70 (HSP-70) are the main causes of PDT tolerance. To obtain a more ideal PDT treatment effect, PS can be delivered together with gene therapy drugs or small molecule inhibitors targeting VEGF or HSP-70 [58]. In addition, NO produced by photostressed tumor cells 
can induce anti-PDT effect and enhance tumor aggressiveness. This can be addressed by codelivery with iNOS inhibitors. These would be described in detail in the section on codelivery treatment [59-61].

\section{Codelivery of PSs and Anticancer Drugs with Nanoparticles}

There are many factors that contribute to decline in photodynamic therapy, including the metastatic tumor at unknown sites, inadequate light delivery, lack of sufficient oxygen and induction of an anti-PDT effect [1]. To overcome these limitations and to improve efficiency, the researchers have combined PDT with other treatments. Codelivery is one of the most common methods to achieve combination therapy and has been widely studied. Currently, common treatment schemes that are amenable to PS codelivery can be divided into the following types: chemotherapy, gene therapy, immunotherapy, photothermal therapy (PTT), hyperthermia (HT), radiotherapy, sonodynamic therapy and multiple drugs codelivery [62-71] (Figure 1). Here, we will mainly introduce the nanocarriers used for the codelivery of PSs and antitumor drugs and discuss how the drugs enhance each other.
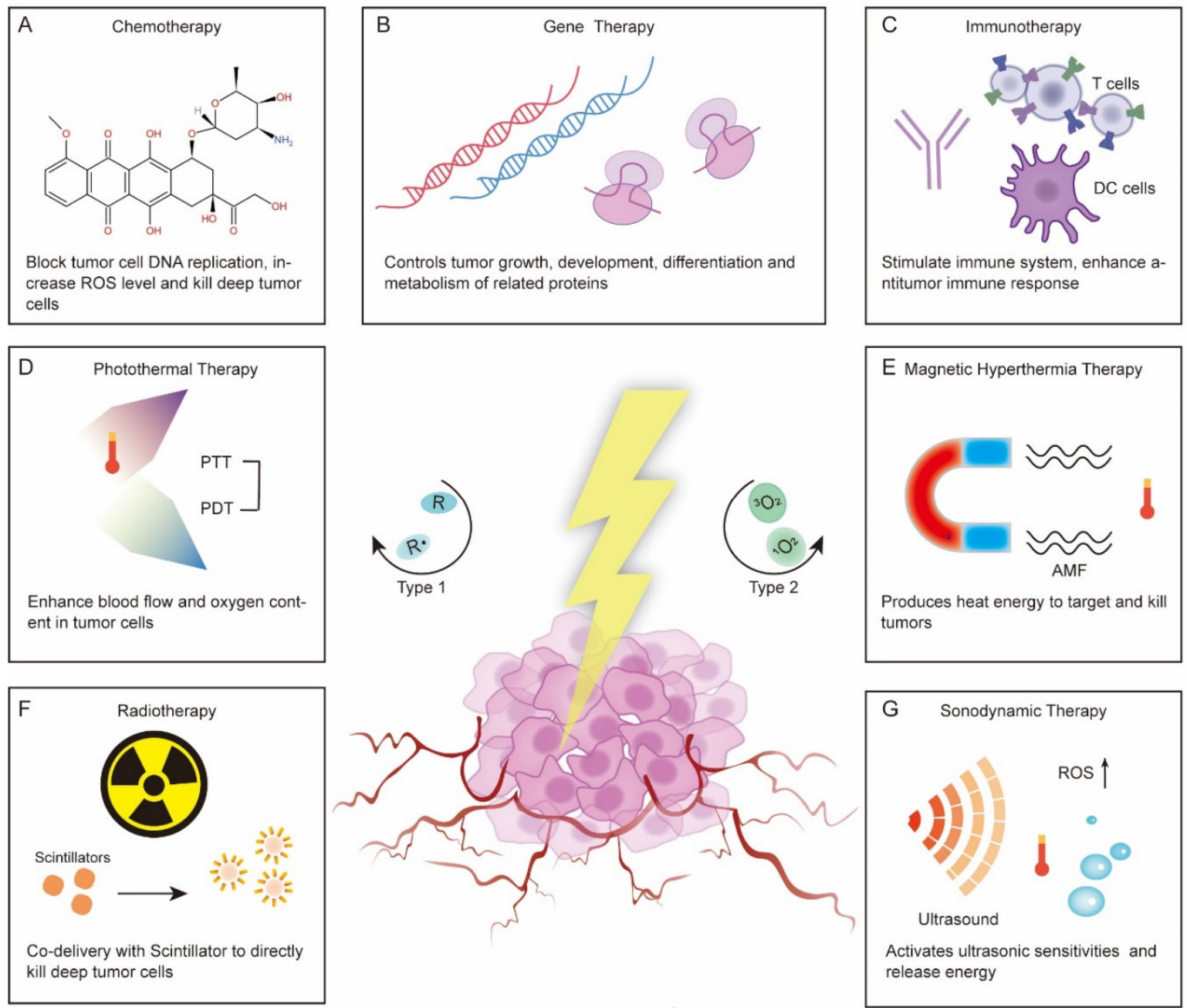

Figure 1. Combination of photodynamic therapy with various therapeutic regimens and possible synergistic antitumor mechanisms. (A) Chemotherapy, (B) Gene therapy, (C) Immunotherapy, (D) Photothermal therapy, (E) Hyperthemia therapy/Magnetic hyperthermia therapy, (F) Radiotherapy, and (G) Sonodynamic therapy.

\subsection{Chemotherapy}

Chemotherapy is a commonly used method for tumor treatment, but systemic toxicity and side effects cause patients to face great pain when receiving treatment, and the efficacy 
is limited by stability, targeting and multidrug resistance [72]. Many reports have proven that the application of targeted delivery vectors can improve the physical and chemical properties of chemotherapy drugs, while combination with PDT can help to improve multidrug resistance and other problems [73,74]. Mechanistically, chemotherapeutic drugs bind to the DNA of tumor cells and block DNA replication, which leads to suppressed cell division and ultimately death [75]. It has also been found that many chemotherapeutic drugs can increase intracellular ROS levels and oxidation-reduction homeostasis of cancer cells, thus enhancing the sensitivity of tumor cells to PDT [76]. On the other hand, light-independent chemotherapy can kill deep-level tumor cells that PDT cannot, while increased tumor vascular permeability induced by PDT can enhance the accumulation of nanomaterials in tumors, thus enhancing the efficacy of chemotherapy $[77,78]$.

Cationic liposomes are widely used in the codelivery system of PSs and chemotherapeutic drugs due to their preferential accumulation in the vascular endothelium [79]. The introduction of porphyrin-phospholipid (PoP), which is a kind of PS-coupled lipid, enables photoprogrammed controlled release of cationic liposomes. ROS produced by irradiation can oxidize unsaturated lipids and accelerates the release of chemotherapeutic drugs [80,81] (Figure 2A). Doxorubicin (DOX) was loaded into PoP liposomes for intravenous injection. Tumor vascular permeability and drug accumulation were significantly increased under near-infrared light, while empty PoP liposomes without drug loading also showed antitumor effects, suggesting that conjugation with phospholipids did not affect the photodynamic effect of PS [82,83]. In the synthesis of PoP liposomes, the selection of PoP and the proportion of other raw materials are crucial to the morphology and serum stability of the liposomes. Generally, a lower content of PoP in the lipid bilayer leads to higher serum stability [84]. Moreover, the dosage needs to be considered. When DOX is loaded in excess, the bilayer of PoP liposomes becomes elliptical due to instability, while loading irinotecan (a camptothecin-derived anticancer drug) does not affect the morphology of the liposomes [62]. In addition, carrier modification can achieve multiple functions; for example, ${ }^{64} \mathrm{Cu}$-labeled POP liposomes can be used for imaging simultaneously with treatment and have been shown to not cause drug leakage [85]. The timing of illumination after POP liposome administration is also important, and studies have shown that the drug accumulates more in tumors at short drug-light intervals [86].

Hypoxia is the cause of drug resistance in both chemotherapy and PDT. The effect of photochemotherapy can be enhanced by codelivery of oxygen carriers [87] or oxygen generators [88] loaded with therapeutic drugs. There are also substances that can serve as both chemotherapeutic agents and oxygen donors. For example, nanoplatinum (Pt), when encapsulated in liposomes with PSs, can provide oxygen as a catalase-like nanoenzyme, while Pt ions leached separately can also exert cytotoxic effects [89]. Although the application of nanocarriers can reduce the toxicity and side effects of chemotherapy drugs, it cannot improve the antitumor tolerance caused by the upregulation of heat shock protein HSP-70 after PDT. Hailong Tian [90] combined quercetin (Qu), a chemotherapy drug with the dual effects of anticancer and heat shock protein inhibition, with IR780. IR780 modified with hydrophilic biotin and Qu were assembled into a delivery carrier in solution, which successfully enhanced the therapeutic effect of PDT by inhibiting the expression of HSP-70. PDT and some chemotherapeutic agents, such as DOX and Pt, can mediate ICD. For example, the combined action of oxaliplatin and PDT was shown to expose calreticulin (CRT) on tumor cells, successfully activating host immunity and creating a suitable microenvironment for subsequent immunotherapy combination [91]. More examples of recently published studies on the codelivery of photosensitizers and chemotherapy drugs based on nanocarriers are illustrated in Table 1. 


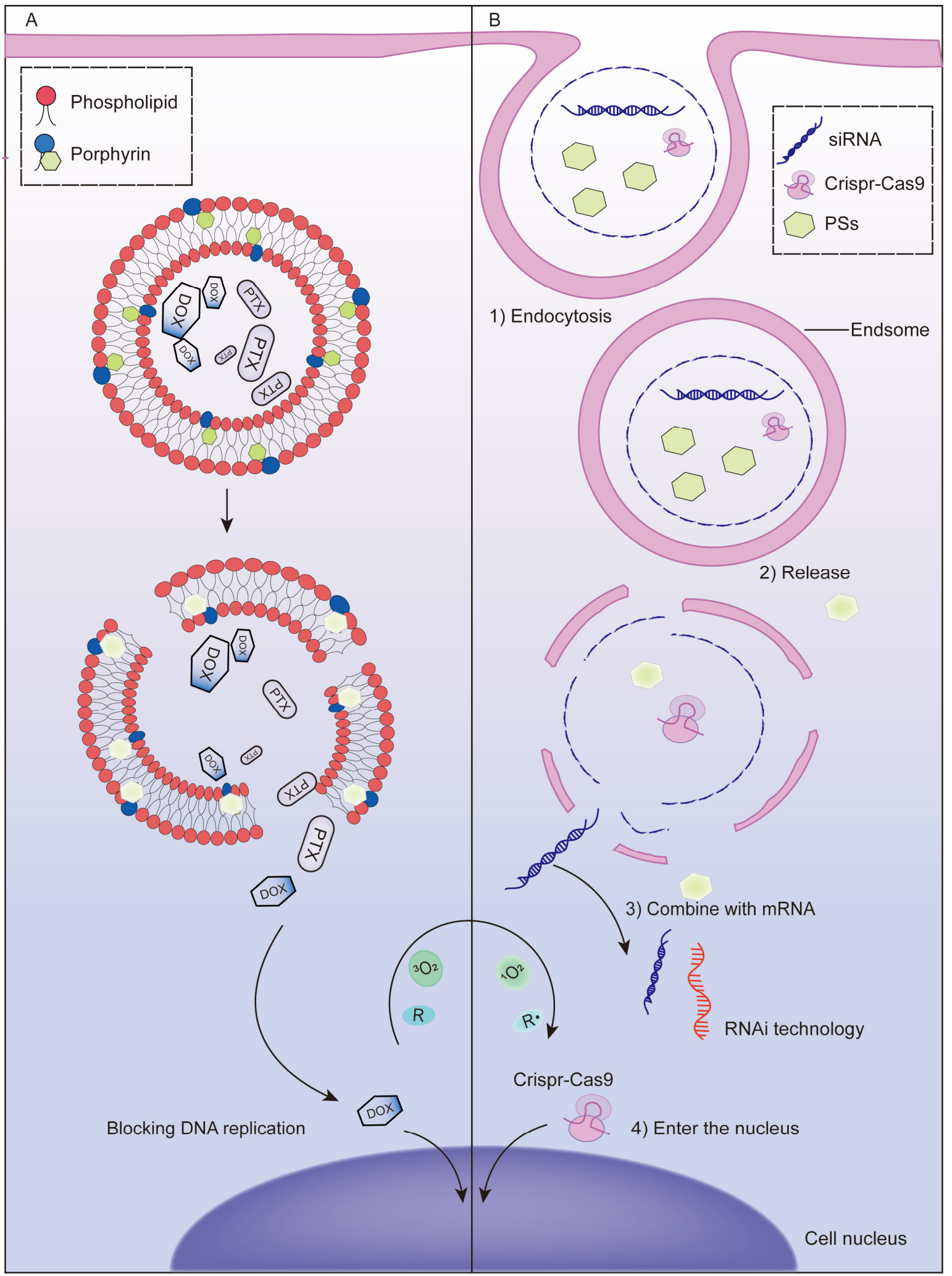

Figure 2. Mechanism of chemotherapy or gene therapy synergistic with PDT to enhance the antitumor effect. (A) Diagrammatic illustration of the mechanism of PDT-mediated controlled release of chemotherapy drugs. ROS produced by irradiation can oxidize unsaturated lipids and accelerate the release of chemotherapeutic drugs from porphyrin-phospholipid liposomes. (B) Diagrammatic illustration of the mechanism of photochemical internalization (PCI)-mediated endosome escape of nucleic acid drugs. When a photosensitizer is activated by an exogenous light, ROS can be produced rapidly in a short time, destroy the membrane of the intracellular body and release therapeutic genes in the cytoplasm. 
Table 1. Codelivery of photosensitizers and chemotherapy drugs based on nanocarriers.

\begin{tabular}{|c|c|c|c|c|c|c|}
\hline Nanoparticle & Photosensitizers & Chemotherapy Drugs & Tumor & Data Sources & Findings & Ref \\
\hline $\begin{array}{l}\text { Azobenzene-containing } \\
\text { conjugated polymers- } \\
\text { camptothecin-chlorin e6 NPs } \\
\text { (CPs-CPT-Ce6) }\end{array}$ & Chlorin e6 (Ce6) & Camptothecin (CPT) & HeLa & In vitro, Animals & $\begin{array}{l}\text { - The }-\mathrm{N}=\mathrm{N}-\text { functional groups in azobenzene could be } \\
\text { reduced and cleaved by AZO reductase in tumor hypoxia, } \\
\text { promoting ROS production. } \\
\text { Controlled release of CPT through the reduction of CPs by } \\
\text { AZO reductase. }\end{array}$ & [92] 2018 \\
\hline $\begin{array}{l}\text { Cyclic pentapeptide cRGDfk } \\
\text { and Chlorin e6 conjugated silk } \\
\text { fibroin (SF)-based NPs }\end{array}$ & Chlorin e6 (Ce6) & 5-Fluorouracil (5-FU) & MGC-803 & In vitro, Animals & $\begin{array}{l}\text { - } \quad \text { cRGDfk specifically targets and binds overexpressed } \alpha_{\mathrm{v}} \beta_{3} \\
\text { integrin receptors on MGC-803 cells to increase tumor } \\
\text { aggregation of the drug. } \\
\text { Induced high reactive oxygen species generation and } \\
\text { produced a good antitumor effect. }\end{array}$ & [93] 2018 \\
\hline $\begin{array}{l}\text { DOX- and perfluorocarbon } \\
\text { (PFC)- loaded fluorinated } \\
\text { aza-boron-dipyrromethene } \\
\text { (PDNBF) NPs }\end{array}$ & $\begin{array}{l}\text { Fluorinated aza-boron- } \\
\text { dipyrromethene } \\
\quad \text { (NBF) }\end{array}$ & DOX & $4 \mathrm{~T} 1$ & In vitro, Animals & $\begin{array}{l}\text { - High doxorubicin loading efficiency (25\%). } \\
\text { PDNBF NPs could be effectively enriched at the tumor site, } \\
\text { and DOX could be explosively released by laser irradiation. } \\
\text { - Significantly inhibited tumor growth and mediated in vivo } \\
\text { ultrasound and photoacoustic imaging. }\end{array}$ & [94] 2020 \\
\hline $\begin{array}{l}\text { Pluronic F127 encapsulated } \\
\text { halogenated } \\
\text { boron-dipyrromethene NPs } \\
\left(\mathrm{LBBr}_{2} \mathrm{NPs} \text { and } \mathrm{LBCl}_{2} \mathrm{NPs}\right)\end{array}$ & $\begin{array}{l}\text { Halogenated } \\
\text { boron-dipyrromethene } \\
\left(\mathrm{BDPBr}_{2} \text { and } \mathrm{BDPCl}_{2}\right)\end{array}$ & Lenvatinib & Hep3B, Huh7 & In vitro & $\begin{array}{l}\text { - Improved the water solubility of drugs } \\
\text { - Controlled release through pH response and enhanced the } \\
\text { targeting of chemotherapy drugs. } \\
\text { Significantly inhibited tumor growth by } \\
\text { chemotherapy/photodynamic cotherapy. }\end{array}$ & [95] 2021 \\
\hline $\begin{array}{l}\text { Lactobionic } \\
\text { acid-catalase-cis-aconitic } \\
\text { anhydride-linked doxorubicin } \\
\text { @ chlorin e6 } \\
\text { (LA-CAT-CAD@Ce6) }\end{array}$ & Chlorin e6 (Ce6) & $\begin{array}{l}\text { cis-Aconitic } \\
\text { anhydride-linked } \\
\text { doxorubicin } \\
\text { (DOX precursor) }\end{array}$ & EMT6 & In vitro, Animals & $\begin{array}{l}\text { - Lactobionic acid acted as an active targeting ligand to increase } \\
\text { cellular internalization. } \\
\text { - Controlled release through pH response. } \\
\text { Decreased the expression of hypoxia-inducible factor- } 1 \alpha \text { and } \\
\text { improved the therapeutic effect. }\end{array}$ & [96] 2020 \\
\hline $\begin{array}{c}\text { Pyropheophorbide } \\
\text { a-polyethylene glycol } 2000 \\
\text { (Ppa-PEG2k) }\end{array}$ & Pyropheophorbide a (Ppa) & $\begin{array}{l}\text { ROS-responsive oleate } \\
\text { prodrug of } \\
\text { paclitaxel (PTX) }\end{array}$ & $\mathrm{A} 549,4 \mathrm{~T} 1$ & In vitro, Animals & $\begin{array}{l}\text { - Enhanced the loading efficiency and avoided the quenching } \\
\text { effect (ACQ) of PSs. } \\
\text { ROS produced by PDT controlled the release of chemotherapy } \\
\text { drug PTX. }\end{array}$ & [97] 2019 \\
\hline
\end{tabular}


Table 1. Cont.

\begin{tabular}{|c|c|c|c|c|c|c|}
\hline Nanoparticle & Photosensitizers & Chemotherapy Drugs & Tumor & Data Sources & Findings & Ref \\
\hline $\begin{array}{l}\text { Poly (oligo (ethylene glycol) } \\
\text { methacrylate)-Paclitaxel } \\
\text { @Chlorin e6 NPs }\end{array}$ & Chlorin e6 (Ce6) & $\begin{array}{c}\text { B-sensitive } \\
\text { polymer-paclitaxel (PTX) }\end{array}$ & $\mathrm{T} 24$ & In vitro, Animals & $\begin{array}{l}\text { - Photointernalization (PCI) accelerated the uptake of NPs by } \\
\text { tumor cells. } \\
\text { Tumor growth was significantly inhibited in a PDX model, } \\
\text { and the inhibition rate was more than } 98 \% \text {. }\end{array}$ & [98] 2021 \\
\hline $\begin{array}{l}\text { Polyethylene glycol-peptide- } \\
\text { poly( } \omega \text {-pentadecalactone-co- } \\
\text { N-methyldiethyleneamine-co- } \\
\text { 3,3'-thiodipropionate) } \\
\text { (PEG-M-PPMT) } \\
\text { nanoparticles (NPs) }\end{array}$ & Chlorin e6 (Ce6) & Sorafenib (SRF) & A549 & In vitro, Animals & $\begin{array}{l}\text { - Increased serum stability of Ce6 and SRF and enhanced drug } \\
\text { aggregation in tumors by EPR. } \\
\text { Overexpressed MMP-2 in tumor extracellular matrix could } \\
\text { partially shed PEG from NPs and form smaller particles that } \\
\text { penetrate into tumor tissue. } \\
\text { Acidic pH and high intracellular ROS levels accelerated drug } \\
\text { release and rapidly killed tumor cells. }\end{array}$ & [99] 2020 \\
\hline $\begin{array}{c}\text { (Phenylboronic } \\
\text { acid }_{4}-\mathrm{E}_{2} \mathrm{E}_{2} \text {-Protoporphyrin } \\
\text { IX-(Lipoic acid })_{2}\end{array}$ & Protoporphyrin IX (PpIX) & Paclitaxel (PTX) & A549 & In vitro, Animals & $\begin{array}{l}\text { - PTX blocks mitosis and makes cells stay at G2/M, prolonging } \\
\text { the destruction time of nuclear membrane and promoting the } \\
\text { accumulation of photosensitizer in the nucleus. } \\
\text { PDT enhanced the internalization and release rate of PTX by } \\
\text { destroying lysosomes. }\end{array}$ & [100] 2020 \\
\hline
\end{tabular}




\subsection{Gene Therapy}

The rapid development of nanodelivery systems has improved the penetration ability of cells and tissues and stability of exogenous genes under physiological conditions, allowing gene therapy technology to break through previous bottlenecks and enable clinical application [102,103]. The combination of gene therapy and PDT offers a high degree of precision based on complementary base pairs, which most other therapeutic combinations lack. Exogenous genes are required to efficiently enter cells and successfully escape intracellular bodies before they can play a therapeutic role, which poses great challenges to the material properties of delivery vectors [104]. Programmable vectors have been proposed to solve this problem to some extent and are commonly released under internal stimuli such as enzymes under special $\mathrm{pH}$ conditions. Photochemical internalization (PCI) is an intracellular delivery technique using an exogenous light as a stimulus. After activation of PS, ROS can be rapidly produced within a short time to destroy the membrane of the intracellular body and release therapeutic agents such as nucleic acid drugs in the cytoplasm $[105,106]$ (Figure 2B). This external light-dependent regulation is more controllable and stable than the internal response-dependent system and can achieve higher spatially controlled and targeted gene delivery [107]. Another type of photoprogrammed gene regulation uses PDT active nanomaterials as gene delivery vectors, such as PPBP, the black phosphorus (BP) nanosheets prepared with PEG and PEI modification, a black scale nanomaterial that shows PDT activity under light and then specifically degrades to release siRNA in a high ROS and acidic tumor environment to achieve targeted delivery [108].

Hypoxia influences PDT, while upregulation of VEGF and HSP-70 leads to PDT tolerance. Changing the expression of these proteins by gene therapy can help resolve these challenges to some extent and enhance the sensitivity of tumor cells to PDT. HIF $1 \alpha$ is a hypoxia-inducible factor that plays a key role in tumor cell proliferation and angiogenesis [109]. Zheng WH [110] used anisamide-targeted lipid-calcium-phosphate (LCP) nanoparticles to achieve codelivery of protoporphyrin IX (PpIX) and HIF-1 $\alpha$ siRNA. The results showed that HIF1 $\alpha$ downregulation not only directly inhibited tumor cell generation but also promoted ROS production in the tumor environment, thereby enhancing PDTmediated apoptosis. Nrf2 is a key antioxidation regulator that prevents ROS accumulation and promotes angiogenesis. Deng S [111] codelivered CRISPR-Cas9 ribonucleoprotein (RNP) with Ce6, ROS generated by the latter caused release of Cas9/sgRNA into cytoplasm, resulting in Nrf2 interference and preventing tumor cells escaping from ROS-mediated killing. In terms of improving PDT-induced tolerance, Jang Y [112] prepared a DOXsiVEGF-NPS/Ce6-MBS complex coloaded with VEGF siRNA and Ce6 for the treatment of squamous cell carcinoma. Under the action of VEGF siRNA, tumor angiogenesis was significantly reduced, and the antitumor effect was improved. Similar results were reported in Cao Y [113], the $\mathrm{MnO}_{2}$ nanosheet was first surface decorated with $\mathrm{Cu}_{2-\mathrm{x}} \mathrm{S}$ and then loaded with HSP-70 siRNA to form $\mathrm{MnO}_{2} / \mathrm{Cu}_{2-} \mathrm{X}$-HSP-70-siRNA, which mediated the heat shock response and showed superior synergistic antitumor ability. In addition, the use of therapeutic genes to regulate the expression of proteins related to the growth, development, differentiation and metabolism of tumor cells can enhance the effect of PDT or supplement the limitations of PDT. For example, gene therapy can activate the body's immune system to treat metastatic cancer [114] and inhibit epithelial-mesenchymal transition (EMT) to avoid tumor recurrence [115]. Overall, the diversity of cancer-causing genes and the complexity of pathogenesis, as well as the innate differences of individuals, give gene therapy and PDT to infinite possibilities in combination. More examples of recently published studies on the codelivery of photosensitizers and gene therapy drugs based on nanocarriers are illustrated in Table 2. 
Table 2. Codelivery of photosensitizers and gene therapy drugs based on nanocarriers.

\begin{tabular}{|c|c|c|c|c|c|c|}
\hline Nanoparticle & Photosensitizers & Gene Therapy Drugs & Tumor & Data Sources & Findings & Ref \\
\hline $\begin{array}{l}\text { Chlorin } \\
\text { e6-DNAzyme/Cu(I)1,2,4-tri- } \\
\text { azolate nanoscale coordination } \\
\quad \text { polymers } \\
\text { (Ce6-DNAzyme/[Cu(tz)] CPs) }\end{array}$ & Chlorin e6 (Ce6) & $\begin{array}{l}\text { Early Growth Response } \\
\text { Factor-1 (EGR-1) targeted } \\
\text { DNAzyme }\end{array}$ & MCF-7 & In vitro, Animals & $\begin{array}{l}\text { - } \quad[\mathrm{Cu}(\mathrm{TZ})] \mathrm{CPs} \text { and Ce6 induced type } 1 \text { and type } 2 \text { PDT at } 808 \\
\mathrm{~nm} \text { and } 660 \mathrm{~nm} \text {, respectively, enhancing the therapeutic effect } \\
\text { in hypoxia environment (tumor regression rate was } 88.0 \%) \text {. } \\
\text { Ce6-DNAzyme was degraded by glutathione overexpressed } \\
\text { in tumors, resulting in DNAzyme targeted release and } \\
\text { catalytic cleavage of EGR-1 mRNA. }\end{array}$ & [116] 2021 \\
\hline $\begin{array}{l}\text { Cationic guanidylated } \\
\text { porphyrin/siRNA complexes } \\
\text { (H2-PG/siRNA) }\end{array}$ & Porphyrin & $\begin{array}{l}\text { Inhibitor of apoptosis } \\
\text { siRNA (siIAP) }\end{array}$ & MDA-MB-231 & In vitro & $\begin{array}{l}\text { - The H2-PG/siRNA complex promoted siRNA internalization. } \\
\text { Cationic guanidylated modification did not affect the PDT } \\
\text { activity of porphyrin. }\end{array}$ & [117] 2019 \\
\hline $\begin{array}{c}\mathrm{CaCO}_{3} \text { layer modified } \mathrm{MnO}_{2} \\
\text { NPs }\left(\mathrm{Mn} @ \mathrm{CaCO}_{3}\right)\end{array}$ & Indocyanine green (ICG) & $\begin{array}{l}\text { Programmed death } \\
\text { ligand } 1 \text { siRNA (siPD-L1) }\end{array}$ & Lewis & In vitro, Animals & $\begin{array}{l}\text { - Increased oxygen production mediated by } \mathrm{MnO}_{2} \text { and reduced } \\
\mathrm{H}^{+} \text {consumption mediated by } \mathrm{CaCO}_{3} \text { jointly enhanced the } \\
\text { PDT effect. } \\
\text { siPD-L1 silencing and PDT together activated the immune } \\
\text { system, mediating a powerful antitumor immune response. }\end{array}$ & [118] 2019 \\
\hline $\begin{array}{l}\text { (PGL-NH2)2 and fluorocarbon } \\
\text { inert gas of C3F8 grafted } \\
\text { cationic porphyrin } \\
\text { microbubbles (CpMBs)/siRNA }\end{array}$ & Porphyrin & $\begin{array}{l}\text { Pioneer transcription } \\
\text { factor } 1 \text { siRNA (siFOXA1) }\end{array}$ & MCF-7 & In vitro, Animals & $\begin{array}{l}\text { - Enhanced drug loading of photosensitizer and siRNA. } \\
\text { Under the guidance of contrast-enhanced ultrasound, the } \\
\text { accumulation of local microbubbles in tumors was } \\
\text { significantly increased through the ultrasound-induced } \\
\text { superpore effect. } \\
\text { The codelivery system showed superior breast cancer } \\
\text { inhibition. }\end{array}$ & [119] 2018 \\
\hline $\begin{array}{c}\left(\mathrm{NaYF}_{4}: \mathrm{Yb}, \mathrm{Er}\right) \text { upconversion } \\
\text { NPs (UCNPs) }\end{array}$ & $\begin{array}{l}\text { 5,10,15,20-tetrakis } \\
\quad(1-\text { methyl } \\
\text { pyridinium-4-yl) } \\
\text { porphyrin }\left(\mathrm{TMPyP}_{4}\right)\end{array}$ & $\begin{array}{l}\text { ssDNA with chitosan } \\
\text { aptamer (AS1411) and } \\
\text { chitosan-targeted } \\
\text { DNAzyme }\end{array}$ & MCF-7 & In vitro, Animals & $\begin{array}{l}\text { - The multivalence of the ssDNA endowed the UCNPs with } \\
\text { high recognition and loading capacity of TMPyP4 and } \\
\text { DNAzymes. }\end{array}$ & {$[120] 2020$} \\
\hline $\begin{array}{l}\text { Versatile function of cationic } \\
\text { phosphonium-conjugated } \\
\text { polythiophenes }\end{array}$ & Polythiophenes & Luciferase gene siRNA & MDA-MB-231 & In vitro & $\begin{array}{l}\text { - The vector effectively self-assembled with siRNA and } \\
\text { mediated effective gene silencing ( } 35 \% \text { and } 52 \% \text { gene } \\
\text { silencing efficiencies, respectively). } \\
\text { After successful delivery of siRNA, the photoactivity of the } \\
\text { vector was restored, which could mediate further PDT. }\end{array}$ & [121] 2020 \\
\hline
\end{tabular}


Table 2. Cont.

Nanoparticle

Photosensitizers

Gene Therapy Drugs

Tumor

Data Sources

- Cationic photosensitive drugs were polymerized by an ROS splitting linker to achieve separation in space and avoid ACQ effects and could be used as a carrier to deliver siRNA.

Hypoxia-inducible actor- $1 \alpha$ siRN

$\mathrm{H} 22$ $($ siHIF-1 $\alpha)$

- Mediated effective intracellular internalization and gene silencing efficiency $(60 \%)$, synergistic enhancement of phototoxicity.

PDT effectively induced cell death with $95 \%$ mortality.

- As a delivery carrier of siRNA, it can successfully escape from endosomes and play a therapeutic role, with gene silencing efficiency up to $83 \%$.

- It presented triple functions, namely, imaging, PDT and PCI.

- $\quad$ Alternating low and high doses of light drove siRNA internalization and PDT, respectively.

- The liver and lung metastasis of HeLa cells were successfully
Vascular endothelial rowth factor (VEGF) siVEGF
In vitro, Animals
Ref

\section{Dendritic arginine-rich peptide} conjugated with acid (ALS) therapeutic effect was superior. 


\subsection{Immunotherapy}

PDT can activate the body's immune response in two ways: one is to induce an acute inflammatory response of the host and release various proinflammatory signals; the other is to trigger ICD by injured or dead tumor cells to release damage-associated molecular patterns (DAMPs) and neoantigens as danger signals [3,124]. Although the immune response mediated by PDT is not enough to kill tumor cells, it can create a reconstructed immune microenvironment for further antitumor immunotherapy [63].

Immune adjuvants are a class of immune-stimulating molecules that activate tumorspecific immune responses by interacting with Toll-like receptors (TLRs) on antigenpresenting cells (APCs) [125]. The combination of immune adjuvant and PDT has the dual ability to activate the immune system. A nanometal organic framework (nMOF) formed by direct self-assembly of metal ions and PSs is often used as a codelivery carrier and is characterized by a high loading efficiency and good biocompatibility [126]. Cai Z [127] prepared PCN-ACF-CpG@HA NPs loaded with the immune adjuvant CPG by combining PS tetrakis (4-carboxyphenyl) porphyrin $\left(\mathrm{H}_{2} \mathrm{TCPP}\right)$ with zirconium ions to target tumors with high expression of the CD44 receptor. CPG and PDT together mediated a strong antitumor immune response, with significantly higher CD8+ and CD4+ $\mathrm{T}$ cell infiltration at the tumor site than that in the control group. Similarly, the cationic W-TBP designed by Ni K [128] based on nMOF can directly adsorb negatively charged CPG through electrostatic action, promote its internalization and DC maturation, and enhance antigen presentation in coordination with PDT-induced CRT exposure. In addition to treating tumors in situ, this codelivery combination kills distant metastatic cancer cells. Xia Y [129] evaluated the efficacy of CPG combined with the PS verteporfin in the treatment of 4T1 metastatic breast cancer; the results showed that the activation of DC cells was significantly increased, and the tumor volume of tumor-bearing mice was smaller than that of other control groups. Xu C [130] also achieved similar results in the treatment of local and metastatic B160F10 melanoma, which was enhanced by promoting DC recruitment and cytotoxic $\mathrm{T}$ cell infiltration at the tumor site. Exogenous antigens can also activate immune responses. Ovalbumin (OVA), a commonly used model antigen, can be used as a supplement to immune stimulation induced by PDT. The effect of such codelivery was evaluated in the studies of Huang R [131] and Ding B [132], both of which showed synergistic immune enhancement.

Immune checkpoint therapy has made significant breakthroughs in recent years and can effectively improve the immune system's response to tumors. At present, several immune checkpoint inhibitors have been approved by the FDA for clinical treatment [133]. Tumor vascular abnormalities and the immunosuppressive tumor microenvironment (TME) caused by indoleamine 2,3-dioxygenase 1 (IDO1) seriously affect the efficacy of PDTmediated immunotherapy. Codelivery of PSs with IDO1 inhibitors is beneficial for amplifying the effects of photodynamic immunotherapy. Combinations that have been reported include ferritin and polyethylene glycol-PLGA (PEG-PLGA) coloaded with $\mathrm{ZnF}_{16} \mathrm{Pc}$ and IDO inhibitor NLG919 [134] or Ce6, tyrosinase inhibitor axitinib (AXT), IDO1 inhibitor dextro-1-methyltryptophan (1MT) and human serum albumin self-assembled NPs [135]. These combinations can improve the tumor microenvironment by normalizing tumor blood vessels, improving hypoxia levels, promoting the invasion of immune effector CD8+ T cells in tumors, and reducing the immunosuppressive properties of tumors, which represents a promising tumor treatment strategy. Cytotoxic T-lymphocyte-associated antigen 4 (CTLA4) and programmed death-ligand 1 (PD-L1) are the most common immune checkpoints and are closely related to the immune function of $\mathrm{T}$ cells. Xu J [136] used the self-assembly property of Ce6 and immunoglobulin $\mathrm{G}$ (IgG) in the nanoscale affinity range to bind Ce6 to aPD-L1 or double bind to $\alpha$ PD-L1 and $\alpha$ CTLA- 4 in the immunocheckpoint blocking treatment of glioma in situ and colon cancer. This combination therapy successfully prolonged the survival of tumor-bearing mice and produced a long-term memory response, avoiding tumor recurrence. In addition, zinc phthalocyanine and aCTLA4 have been coadded into microneedles prepared by hyaluronic acid and dextran for skin cancer delivery. This mini- 
mally invasive percutaneous drug delivery platform can also effectively induce an antitumor immune response and avoid the systemic distribution of drugs to reduce toxicity and side effects [137]. Without affecting coloaded drugs, nanodelivery systems targeting important organelles such as mitochondria [138] and the endoplasmic reticulum [139] can be designed to enhance PDT-triggered ICD, thereby enhancing immune activation (Figure 3).

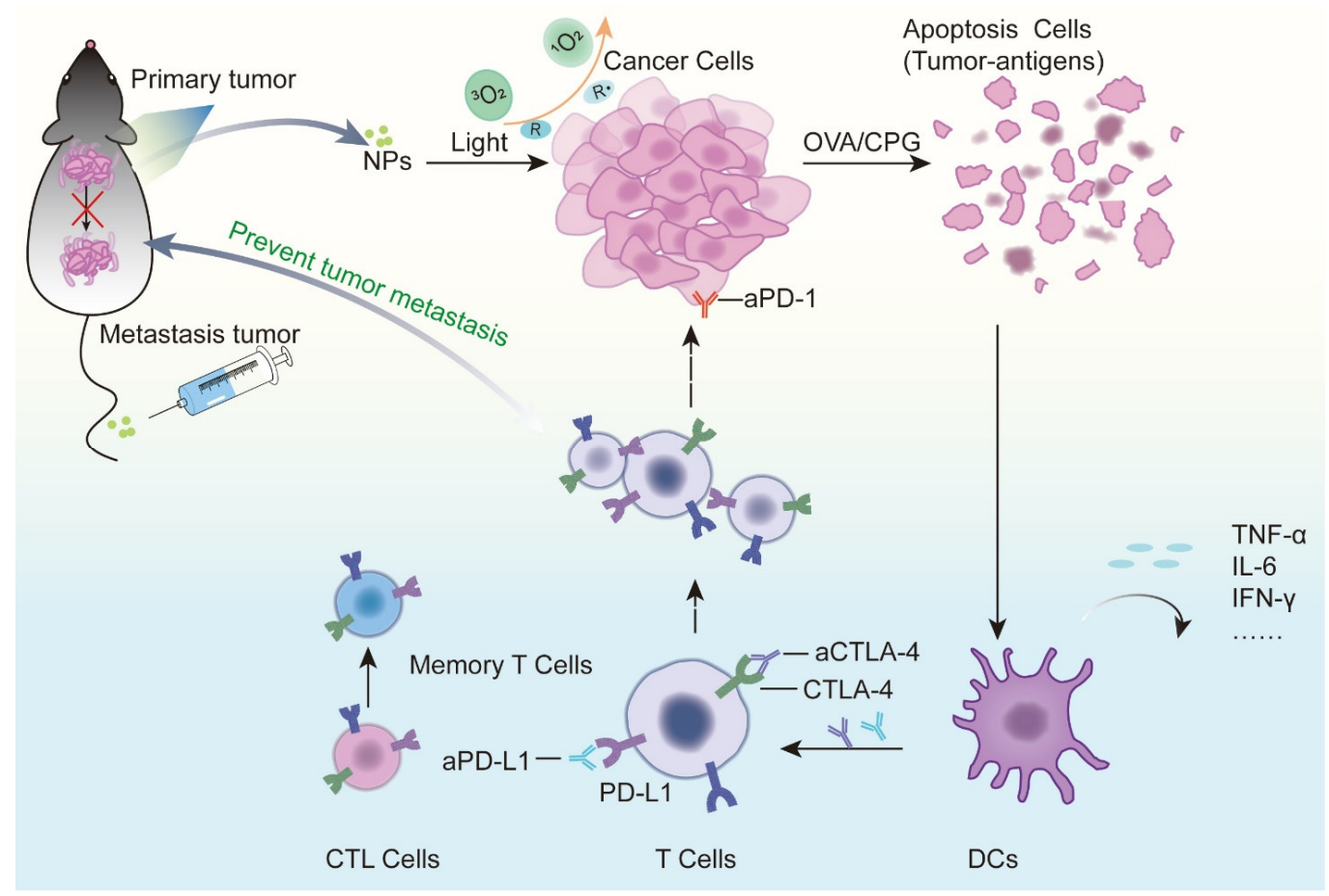

Figure 3. Mechanism by which photodynamic therapy and immunotherapy synergistically enhance antitumor effects. When photosensitizers in tumor sites are activated, they can cause acute inflammation and induce cell apoptosis or necrosis. Dendritic cells mature when stimulated by cytokines released at the site of inflammation and provide antigens to $\mathrm{T}$ lymphocytes in regional lymph nodes. Activated T lymphocytes become effector T cells, which are attracted to chemokines, migrate to the tumor and kill tumor cells. Different types of immunotherapy drugs play a role in different steps of the complete antitumor immune cycle. Codelivery of a photosensitizer with an immune adjuvant or tumor antigen can synergistically enhance the activation of the host immune system and improve the immunosuppressive microenvironment. The codelivery of a photosensitizer with CTLA-4 and PD-L1 monoclonal antibodies can enhance the antitumor immunity effect of T cells. The activation of these immune cells also plays a role in preventing metastasis and recurrence.

Photoimmunotherapy is a tumor-targeting therapy using specific antibodies to tumorassociated receptors chemically coupled with PSs, which is more accurate than conventional PDT and is suitable for tumors at sensitive anatomical sites. Hasan T [140] coupled epidermal growth factor receptor (EGFR) monoclonal antibody Cetuximab with benzoporphyrin derivative for pancreatic ductal adenocarcinoma treatment. The results showed that the photoimmune nanoconjugate (PIN) had a high binding specificity and could rapidly penetrate heteromorphic organoids, providing approximately 16-fold enhancement in molecular targeted NIR photodestruction. Nevertheless, single-receptor targeted therapy may cause tumor subsets with low receptor expression to evade treatment and thus fail to completely ablate tumors. Hasan T [141] further constructs a triple receptor-targeted PIN (TR-PIN), cetuximab, holo-transferrin, and trastuzumab conferred specificity for EGFR, transferrin receptor (TfR), and human epidermal growth factor receptor 2 (HER-2). Researchers compared the binding ability of TR-PIN to tumor cells with different levels of receptor expression (EGFR, TfR or HER-2), and found that TR-PIN has the ability to recognize multiple tumor targets, effectively photodynamically eradicating different tumor subsets and reducing escape. More examples of recently published studies on the codelivery of photosensitizers and immunotherapy drugs based on nanocarriers are illustrated in Table 3. 
Table 3. Codelivery of photosensitizers and immunotherapy drugs based on nanocarriers.

\begin{tabular}{|c|c|c|c|c|c|c|}
\hline Nanoparticle & Photosensitizers & Immunotherapy Drugs & Tumor & Data Sources & Findings & Ref \\
\hline $\begin{array}{l}\text { Ce6-Gold } \\
\text { nanoclusters-PEG2000-CD3 } \\
\text { antibody-cytokine-induced } \\
\text { killer cell NPs }\end{array}$ & Chlorin e6 (Ce6) & CD3 antibody & MGC-803 & In vitro, Animals & $\begin{array}{l}\text { - The fluorescence intensity of GNCS-CE6 was approximately } \\
4.5 \text { times that of GNCs, thereby mediating a stronger PDT } \\
\text { effect. } \\
\text { Increased drug aggregation at the tumor site by targeting CIK } \\
\text { cells. }\end{array}$ & [142] 2018 \\
\hline $\begin{array}{l}\text { Human-induced pluripotent } \\
\text { stem cells loaded with } \\
\mathrm{MnO}_{2} @ \text { Chlorin e6 NPs } \\
\text { (iPS-MnO } \mathrm{MnC}_{2} @ \text { Ce6) }\end{array}$ & Chlorin e6 (Ce6) & $\begin{array}{l}\text { Tumor antigens of } \\
\text { human-induced } \\
\text { pluripotent stem cells }\end{array}$ & Lewis & In vitro, Animals & $\begin{array}{l}\text { - iPS promoted the aggregation of nanoparticles at the tumor } \\
\text { site and could be lysed by ROS produced by PDT to release } \\
\text { tumor antigens. } \\
\mathrm{MnO}_{2} \text { interacted with } \mathrm{H}_{2} \mathrm{O}_{2} \text { to release oxygen and alleviated } \\
\text { tumor hypoxia. }\end{array}$ & [143] 2020 \\
\hline $\begin{array}{l}\text { Chlorin e6- and } \\
\text { imiquimod-loaded } \\
\text { upconversion NPs } \\
\text { (UCNPs-Ce6-R837 NPs) }\end{array}$ & Chlorin e6 (Ce6) & Imiquimod (R837) & CT26 & In vitro, Animals & $\begin{array}{l}\text { - Lanthanide ions in UCNP nanoparticles could transform long } \\
\text { near-infrared light into shorter wave light, improving tissue } \\
\text { permeability. } \\
\text { Toll-like receptor } 7 \text { agonist R837 was used as an adjuvant for } \\
\text { enhanced antitumor immune response. }\end{array}$ & [144] 2017 \\
\hline $\begin{array}{l}\text { Diblock copolymer } \\
\text { azide-modified polyethylene } \\
\text { glycol block polyaspartic } \\
\text { acid(benzylamine) (Azide } \\
\text { PEG-Pasp(Bz) micelles }\end{array}$ & $\begin{array}{c}\text { Zinc phthalocyanine } \\
(\mathrm{ZnPc})\end{array}$ & $\begin{array}{l}\text { Mal-GGPLGVRG-Pra } \\
\text { peptide modified aPD-L1 }\end{array}$ & B16-F10 & In vitro, Animals & $\begin{array}{l}\text { - Dual corresponding functions of } \mathrm{pH} \text { and MMP-2 responses } \\
\text { enhanced the aggregation of NPs in tumor cells. } \\
\text { - The blood circulation of NPs was prolonged, and their } \\
\text { antitumor ability was enhanced. }\end{array}$ & [145] 2021 \\
\hline $\begin{array}{l}\text { Serum albumin-coated } \\
\text { boehmite B NPs }\end{array}$ & Chlorin e6 (Ce6) & $\begin{array}{l}\text { Bee Venom Melittin } \\
\text { (MLT) }\end{array}$ & $4 \mathrm{~T} 1$ & In vitro, Animals & $\begin{array}{l}\text { - Significantly reduced the hemolysis caused by MLT and } \\
\text { decreased the toxic side effects. } \\
\text { MLT enhanced immunogenic cell death and dendritic cell } \\
\text { activation, coactivating antitumor immunity with PDT. }\end{array}$ & [5] 2019 \\
\hline
\end{tabular}




\subsection{Photothermal Therapy (PTT)}

Additionally, as a minimally invasive treatment, PTT has certain similarities with PDT. Photothermal agents concentrated at the tumor site absorb laser radiation energy and convert light energy into hyperthermia, resulting in the thermal ablation of adjacent cells. PTT enhances the effect of PDT, mainly by improving blood flow and increasing oxygen content in tumors [146] (Figure 4A).

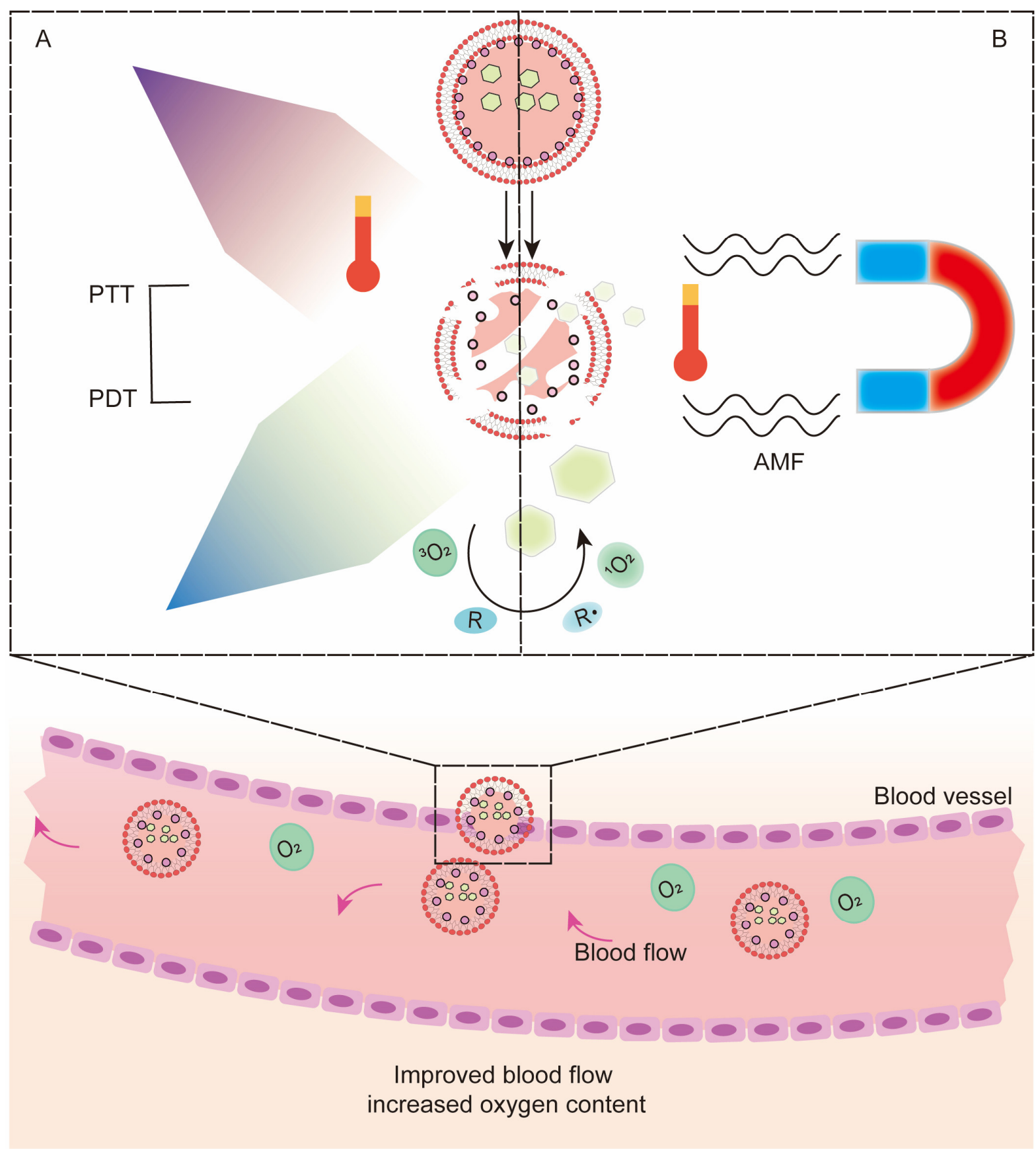

Figure 4. Mechanism of photodynamic therapy combined with photothermal therapy, hyperthermia and magnetic hyperthermia in synergistic enhancement of the antitumor effect based on codelivery systems. (A) When light-activated photothermal agents, (B) or alternating magnetic fields are applied to magnetic nanoparticles, heat is generated at the tumor site, increasing blood flow and synergistically enhancing PDTSome photothermal agents of inorganic materials themselves can be used as nanocarriers, which makes the combination of PTT and PDT convenient. Gold nanorods have been used as carriers with photothermal conversion capability, and the joint delivery of DOX and PS ICG can simultaneously achieve 
chemo-PTT-PDT triple therapy [69]. Gold nanocages [147] show strong absorption in the NIR region, and their empty interior and porous walls are suitable for encapsulating PSs. Bo Tian et al. [148] coupled Ce6 on PEG-functionalized GO (GO-PEG-CE6). The photothermal effect of GO promoted the transfer of Ce6, and its destruction effect on cancer cells was significantly better than that of free Ce6. The photothermal agent plasma copper sulfide $\left(\mathrm{Cu}_{2}-\mathrm{XS}\right)$ has also been reported to have photodynamic properties [149], allowing the combination of PTT and PDT to be achieved simultaneously, and has been verified in in vitro cultured melanoma cells and mouse melanoma models. The poor photostability and potential long-term toxicity of inorganic nanomaterials limit their clinical application, so more materials with good biocompatibility and high stability have been developed as alternatives. The conductive polymer polypyrrole is a material with relatively high biocompatible photostability and photothermal conversion efficiency, using polyacrylamide (PAH), polyacrylic acid (PAA) and $\mathrm{AlPCS}_{4}$. Further modification of polypyrrole resulted in a more stable AlPCS $\mathrm{PPPyCONH}_{4} \mathrm{PAH}-\mathrm{PAA}$ nanoneedle complex in a physiological environment. The results showed an enhanced synergistic effect, with tumor ablation in mice 14 days after treatment and no recurrence within 30 days [150].

Another more conventional codelivery method is to simultaneously load the photothermal agent and PS or prodrug of PS in nanodelivery systems such as micelles, vesicles, and liposomes. Gang Chen et al. [151] developed CS NPs as codelivery carriers of photothermal agents (IR780) and prodrug of protoporphyrin IX (5-aminolevulinic acid, 5-ALA) for oral administration in the treatment of subcutaneous colon cancer in mice. CS keeps the drug stable even under acidic conditions in the stomach, allowing the drug to successfully accumulate at the tumor site. Mechanistic studies have shown that the oxidative stress response at the tumor site is enhanced, producing more ROS, superoxide and ${ }^{1} \mathrm{O}_{2}$. The enhanced effect of this synergistic administration of light and heat on cancer treatment was also reported in the research of Xiaodong Liu [65]. The high singlet oxygen generation capacity and photothermal conversion efficiency make this treatment strategy more severely phototoxic to both superficial and deep tumor cells.

When the excitation wavelengths of the PS and photothermal agent were different, the complexity of the treatment was greatly increased. To solve this problem, Jing Lin [152] designed a gold vesicle with a strong plasma coupling effect. This gold vesicle was densely packed with monolayer gold NPs, and Ce6 was encapsulated inside. The enhancement of plasma coupling between gold NPs in close proximity lead to a redshift in extinction spectra. Therefore, the photothermal and photodynamic effects could be stimulated simultaneously by a single $671 \mathrm{~nm}$ laser irradiation. Some special materials, such as nano GO, themselves have the dual nature of promoting both PDT and PTT, and their development for PTT can reduce the complexity of material preparation [153]. More examples of recently published studies on the codelivery of photosensitizers and photothermal agents based on nanocarriers are illustrated in Table 4. 
Table 4. Codelivery of photosensitizers and photothermal agents based on nanocarriers.

\begin{tabular}{|c|c|c|c|c|c|c|}
\hline Nanoparticle & Photosensitizers & Photothermal Agents & Tumor & Data Sources & Findings & Ref \\
\hline $\begin{array}{c}\text { Boron dipyrromethene } \\
\text { conjugated hyaluronic acid } \\
\text { polymer NPs (BODIPY-HA NPs) }\end{array}$ & $\begin{array}{l}\text { Boron dipyrromethene } \\
\text { (BODIPY) }\end{array}$ & $\begin{array}{l}\text { Boron dipyrromethene } \\
\text { (BODIPY) }\end{array}$ & $4 \mathrm{~T} 1$ & In vitro & $\begin{array}{l}\text { - BODIPY showed only PTT activity due to P-P stacking after } \\
\text { self-assembly to form NPs. } \\
\text { BODIPY-HA NPs were decomposed into BODIPY-HA } \\
\text { molecules, restoring PDT activity and producing ROS after } \\
\text { internalization by tumor cells. }\end{array}$ & [154] 2021 \\
\hline $\begin{array}{l}\text { 1,2-Distearoyl-sn-glycero-3- } \\
\text { phosphoethanolamine-N- } \\
\text { [carboxy(polyethylene } \\
\text { glycol)-2000]-coated } \\
\text { nanographene oxide-copper } \\
\text { sulfide NPs (pGO-CuS NPs) }\end{array}$ & $\mathrm{GO}, \mathrm{CuS}$ & $\begin{array}{l}\text { Indocyanine green (ICG), } \\
\text { CuS }\end{array}$ & MCF-7 & In vitro & $\begin{array}{l}\text { - Photosensitizer-assembled NPs improved the drug loading } \\
\text { efficiency and stability. }\end{array}$ & [155] 2015 \\
\hline Polypyrrole NPs & Phycocyanin $(\mathrm{Pc})$ & Phycocyanin (Pc) & MDA-MB-231 & In vitro & $\begin{array}{l}\text { - } \quad \text { Pc produced PDT and PTT activity under } 600 \mathrm{~nm} \text { and } \\
900 \mathrm{~nm} \text { laser activation, respectively. } \\
\text { - } \quad \text { It had good synergistic antitumor effects and cell imaging } \\
\text { ability of PDT and PTT. }\end{array}$ & [156] 2017 \\
\hline $\begin{array}{l}\text { Indocyanine green-coated } \\
\text { single-walled carbon nanohorn } \\
\text { NPs (SWNH-ICGs) }\end{array}$ & Indocyanine green (ICG) & Indocyanine green (ICG) & $4 \mathrm{~T} 1$ & In vitro, Animals & $\begin{array}{l}\text { - The stability of ICG was improved, and ICG was protected } \\
\text { from photodegradation. } \\
\text { Under } 808 \mathrm{~nm} \text { laser irradiation, local hyperthermia and a } \\
\text { large number of ROS were produced simultaneously, } \\
\text { effectively inhibiting the growth of } 4 \mathrm{~T} 1 \text { tumors. }\end{array}$ & [157] 2018 \\
\hline $\begin{array}{l}\text { Iridium oxide-manganese } \\
\text { dioxide mineralized Chlorin e6 } \\
\text { conjugated bovine serum } \\
\text { albumin NPs } \\
\left(\mathrm{BSA}-\mathrm{Ce} 6 @ \mathrm{IrO}_{2} / \mathrm{MnO}_{2}\right)\end{array}$ & Chlorin e6 (Ce6) & Iridium oxide $\left(\mathrm{IrO}_{2}\right)$ & $\begin{array}{l}\text { MDA-MB-231, } \\
\text { 4T1, PC3 }\end{array}$ & In vitro, Animals & $\begin{array}{l}\text { - } \mathrm{IrO}_{2} \text { and } \mathrm{MnO}_{2} \text { decomposed endogenous } \mathrm{H}_{2} \mathrm{O}_{2} \text { to alleviate } \\
\text { tumor hypoxia and improve PDT. } \\
\text { - } \mathrm{IrO}_{2} \text { presented excellent photothermal conversion efficiency } \\
(65.3 \%) \text { and high } \mathrm{X} \text {-ray absorption coefficient, enabling NPs } \\
\text { to be used in computer CT and PA imaging. }\end{array}$ & [158] 2020 \\
\hline $\begin{array}{l}\text { Lipid-purpurin } 18 \text { and pure lipid } \\
\text { self-assembled NPs (Pp18-lipos) }\end{array}$ & $\begin{array}{l}\text { Lipid-purpurin } 18 \\
\quad \text { (Pp18-lipids) }\end{array}$ & $\begin{array}{l}\text { Lipid-purpurin } 18 \\
\quad \text { (Pp18-lipids) }\end{array}$ & $4 \mathrm{~T} 1$ & In vitro, Animals & $\begin{array}{l}\text { - The Pp18-lipos with } 2 \text { mol\% Pp18-lipids can perform PDT } \\
\text { while with } 65 \mathrm{~mol} \% \text { can perform potent PTT. } \\
\text { PTT/PDT synergistically inhibited tumor growth and } \\
\text { enhanced tumor T cell immune response. }\end{array}$ & [159] 2020 \\
\hline
\end{tabular}


Table 4. Cont.

Nanoparticle

Photosensitizers

Photothermal Agents

Tumor

Data Sources

Findings

Ref
Folic acid-polyethylene glycol-coated black phosphorus nanosheets conjugated with copper sulfide (BP-CuS-FA)
Black phosphorus (BP) Copper sulfide (CuS)

Black phosphorus (BP)
$4 \mathrm{~T} 1$

In vitro, Animals
- FA could target tumor cells with FA receptor overexpression and enhance drug aggregation at tumor site.

- BP nanosheets could be degraded by ROS through oxidation processes to reduce toxic and side effects.

- $\quad$ BP-CuS-FA simultaneously mediated synergically enhanced the PDT-PTT antitumor effect and photoacoustic imaging.

- $\quad$ PFC could be used as an artificial blood substitute to effectively increase hypoxia in the tumor microenvironment and enhance PTT and PDT.

Poly(lactic-co-glycolic acid) (PLGA) NPs
IR780 iodide

Perfluorocarbon (PFC)

$4 \mathrm{~T} 1$

In vitro, Animals

- $\quad$ IR780 could simultaneously act as a PS and mediate mitochondrial targeting, disrupt the balance of mitochondrial ROS and induce irreversible apoptosis of tumor cells.

\section{Amino-modified nanomaterial based on MoS2 \\ quantum-dot-doped \\ disulfide-based $\mathrm{SiO}_{2}$ NPs coated with hyaluronic acid and chlorin}

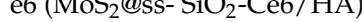

Isoindigo/triphenylamine donor-acceptor-donor conjugated small molecule NPs (IID-ThTPA NPs)

IID-ThTPA

IID-ThTPA
$\mathrm{MoS}_{2}$ quantum dots
In vitro, Animals

- $\quad$ Effectively prolonged the blood circulation time of $\mathrm{MoS}_{2}$

quantum dots and increased the uptake of tumor cells.

- It could also be used for fluorescence/CT/MSOT

- The photothermal conversion efficiency reached $35.4 \%$, and the singlet oxygen yield was $84 \%$

- The ultrahigh singlet oxygen quantum yield of IID-ThTPA NPs originated from the narrow singlet-triplet energy gap of IID-ThTPA.

- $\quad$ ROS generation was promoted through photoinduced effective separation of electron-hole pairs.

$\mathrm{MoSe}_{2} / \mathrm{Bi}_{2} \mathrm{Se}_{3}$ nanoheterostructure

In vitro, Animals

- The photothermal conversion efficiency was increased to $59.3 \%$ by the nanoheterostructure.

- Displayed acid/photothermal sensitive drug release behavior.

Polyethylene glycolated

triphenylphosphine modified hitosan/iron oxide NPs (PEG-CS $/ \mathrm{Fe}_{2} \mathrm{O}_{3} \mathrm{NPs}$ )
Methylene blue (MB)

Iron oxide
HeLa, A549,
MCF-7
- Improved the aggregation in the tumor site, reduce the toxic and side effects on normal tissues.

- Under low-power near-infrared light, NPs produced singlet oxygen, which can damage tumor cells.
[163] 2020 
Table 4. Cont.

\begin{tabular}{|c|c|c|c|c|c|c|}
\hline Nanoparticle & Photosensitizers & Photothermal Agents & Tumor & Data Sources & Findings & Ref \\
\hline $\begin{array}{l}\text { Indocyanine green-grafted gold } \\
\text { nanobipyramids covalently } \\
\text { conjugated with folic acid } \\
\text { (AuBPs@FLA@ICG@FA NPs) } \\
\end{array}$ & Indocyanine green (ICG) & $\begin{array}{l}\text { Gold nanobipyramids } \\
\text { (AuBPs) }\end{array}$ & B16-F10 & In vitro & $\begin{array}{l}\text { Enhanced the overall PTT-PDT efficiency by increasing the } \\
\text { temperature by } 2{ }^{\circ} \mathrm{C} \text { and doubling }{ }^{1} \mathrm{O}_{2} \text { species generation. }\end{array}$ & [166] 2020 \\
\hline $\begin{array}{l}\text { Pardaxin peptide-modified, } \\
\text { indocyanine green-conjugated } \\
\text { hollow gold nanospheres } \\
\text { (FAL-ICG-HAuNS) }\end{array}$ & Indocyanine green (ICG) & Gold nanospheres & CT26 & In vitro, Animals & $\begin{array}{l}\text { - } \quad \text { FAL modification imparted endoplasmic reticulum targeting } \\
\text { capability to NPs } \\
\text { NIR irradiation induced strong ER stress and calcium } \\
\text { reticulin (CRT) exposure, facilitating ICD-mediated } \\
\text { immunotherapy. } \\
\text { - The antigen presentation function of dendritic cells was } \\
\text { enhanced, and CD8+T cell proliferation and secretion of } \\
\text { cytotoxic factors were activated. }\end{array}$ & [139] 2019 \\
\hline $\begin{array}{l}\mathrm{Gd}^{3+} \text { and chlorin e6 loaded } \\
\text { single-walled carbon nanohorns } \\
\text { (Gd-Ce6@SWNHs) }\end{array}$ & Chlorin e6 (Ce6) & $\mathrm{Gd}^{3+}$ & $4 \mathrm{~T} 1$ & In vitro, Animals & $\begin{array}{l}\text { - NPs could migrate from targeted tumors to tumors-draining } \\
\text { lymph nodes, continuously activating DCs, and ultimately } \\
\text { eliminating metastases. }\end{array}$ & [167] 2020 \\
\hline
\end{tabular}




\subsection{Hyperthermia Therapy (HT) and Magnetic Hyperthermia Therapy (MH)}

As one of the emerging noninvasive treatment options, HT may enhance PDT by alleviating hypoxia $[168,169]$. The mechanism is that as temperature increases, blood flow at the tumor site increases and microcirculation improves, thereby increasing tumor oxygenation [170]. $\mathrm{MH}$, also known as magnetic therapy, is based on the heat generated by magnetic NPs (MNPs) under the action of an alternating magnetic field (AMF) to target and kill tumors without harming surrounding healthy tissue [171]. The emergence of MH has made the combination of HT and PDT a possibility, and the generated heat affects deeper tumors, which is beneficial for enhancing PDT [172] (Figure 4B). In terms of codelivery, magnetic nanomaterials can be directly used as carriers or loaded with PS in other carriers. Hongwei $\mathrm{Gu}[66]$ conjugated magnetite $\mathrm{Fe}_{3} \mathrm{O}_{4}$ with porphyrin derivatives, which is highly efficient and has a low systemic toxicity. Huang WC [173] used monocytes derived from bone marrow as carriers to jointly transport Ce6 and oxygen superparamagnetic iron oxide NPs for combined therapy. This is an interesting combination strategy, but the relevant literature is still limited, and researchers need to conduct more in-depth research and discussions. More examples of recently published studies on the codelivery of photosensitizers and hyperthermia agents based on nanocarriers are illustrated in Table 5 . 
Table 5. Codelivery of photosensitizer and hyperthermia agent drugs based on nanocarriers.

\begin{tabular}{|c|c|c|c|c|c|c|}
\hline Nanoparticle & Photosensitizers & Hyperthermia Agents & Tumor & Data Sources & Findings & Ref \\
\hline $\begin{array}{l}\text { Cancer cell membrane-cloaked } \\
\text { Ce6-loaded Janus magnetic } \\
\text { mesoporous organosilica NPs } \\
\text { (CM@M-MON@Ce6) }\end{array}$ & Chlorin e6 (Ce6) & $\begin{array}{l}\text { Magnetic mesoporous } \\
\text { silica nanoparticles } \\
\text { (M-MSNs) }\end{array}$ & $4 \mathrm{~T} 1$ & In vitro, Animals & $\begin{array}{l}\text { - It exhibited the function of REDOX/PH double stimulation to } \\
\text { induce PS release and matrix degradation. } \\
\text { Increased the ability of targeted tumor aggregation and } \\
\text { prolonged blood circulation time. } \\
\text { Enhanced anticancer activity, simultaneously triggering a } \\
\text { series of immunogenic cell death, resulting in a synergistic } \\
\text { tumor-specific immune response. }\end{array}$ & [174] 2019 \\
\hline $\begin{array}{l}\text { Ultramagnetic photosensitive } \\
\text { liposomes }\end{array}$ & Foscan & Iron oxide NPs & SKOV-3 & In vitro, Animals & $\begin{array}{l}\text { - The combination of photodynamic and magnetothermal } \\
\text { therapy triggered the synergistic action of apoptotic signaling } \\
\text { pathways, leading to complete eradication of tumor cells. }\end{array}$ & [175] 2015 \\
\hline $\begin{array}{l}\text { Magneto low-density } \\
\text { nanoemulsion (MLDE) }\end{array}$ & Chlorin e6 (Ce6) & Iron oxide NPs & MCF-7 & In vitro & $\begin{array}{l}\text { Improved the stability and biocompatibility of drugs. } \\
\text { Identified the low-density lipoprotein receptor on the surface } \\
\text { of tumor cells and improved the targeting selectivity of drugs. }\end{array}$ & [176] 2018 \\
\hline
\end{tabular}




\subsection{Radiotherapy}

Band gap materials convert X-rays into light photons in the UV-vis region, which can be used to activate PSs. This is the basis of a combination of PDT and radiation therapy known as X-ray PDT (XPDT) [177,178]. The use of light is one of the limitations of PDT, and the strong tissue penetration of X-rays can compensate for this shortcoming. The method of operation delivers scintillators and PSs together to the tumor site. Under the action of X-rays, scintillators emit persistent light to activate PSs. This strategy can also produce good therapeutic effects for deep tumors [179], and the therapeutic effect depends to some extent on the energy transfer efficiency of the scintillator. The primary choices of scintillators are rare earth materials [180-182] with high photon conversion rates and some metallic materials [183], in addition to a few nonmetallic materials [184] and even quantum dots [185].

Another factor affecting the therapeutic effect is the distance between the PS and the scintillator. One approach is to physically package PS in a coating bound to the scintillator by electrostatic or hydrophobic means or to load both the scintillator and PS into NPs [186,187]; for example, the combination of protoporphyrin IX (PpIX) and scintillator $\mathrm{LaF}_{3}: \mathrm{Ce}^{3+}$ coloaded in PEG-PLGA was shown to exhibit highly efficient loading and high stability under physiological conditions [188]. Physical combination has a certain risk of missing the target, whereas chemical bonding based on covalent bonds or conjugation is complex but more stable. K. K. Popovich [67] coated $\mathrm{CeF}_{3}: \mathrm{Tb}^{3+}$ with PpIX-coupled $\mathrm{SiO}_{2}$. The monodisperse $\mathrm{SiO}_{2}$ coating had high energy transfer efficiency and protected the scintillator encapsulated within it [189].

The combination of a scintillator and PS solves the problem of light sources, but it is still subject to the strong oxygen dependence of PDT. Zhang C [190] was inspired to integrate scintillators and semiconductor quantum dots with unique optical properties into ionizing radiation-induced PDT synchronous radiotherapy. The addition of a PS without traditional effects reduces the oxygen dependence of the complex, which can subsequently produce a process similar to type I PDT under ionizing radiation. Chuang YC [191] introduced the annealing process to achieve PS-free PDT. The yttrium oxide nanoscintillation complex coated with a silica shell $\left(\mathrm{Y}_{2} \mathrm{O}_{3}: \mathrm{Eu} @ \mathrm{SiO}_{2}\right)$ was subjected to X-ray irradiation and subsequent annealing, and then, photodynamic effects were promoted to mediate tumor cell damage in conjunction with radiotherapy.

Radionuclide-mediated Cerenkov luminescence is a phenomenon produced by the interaction of high-speed charged particles with the surrounding medium. The codelivery of radionuclides with PSs has been reported in several studies to have antitumor effects and prolong the survival of tumor-bearing mice. In addition to mediating Cerenkov luminescence, radionuclides can directly kill tumor cells [192,193]. Although this combination has achieved some success in the treatment of deep tumors, there are still many shortcomings to be overcome, such as the blueshift of the low-energy radiation emission spectrum to the ultraviolet region. More examples of recently published studies on the codelivery of photosensitizers and scintillators/radionuclides based on nanocarriers are illustrated in Table 6. 
Table 6. Codelivery of photosensitizers and scintillators/radionuclides based on nanocarriers.

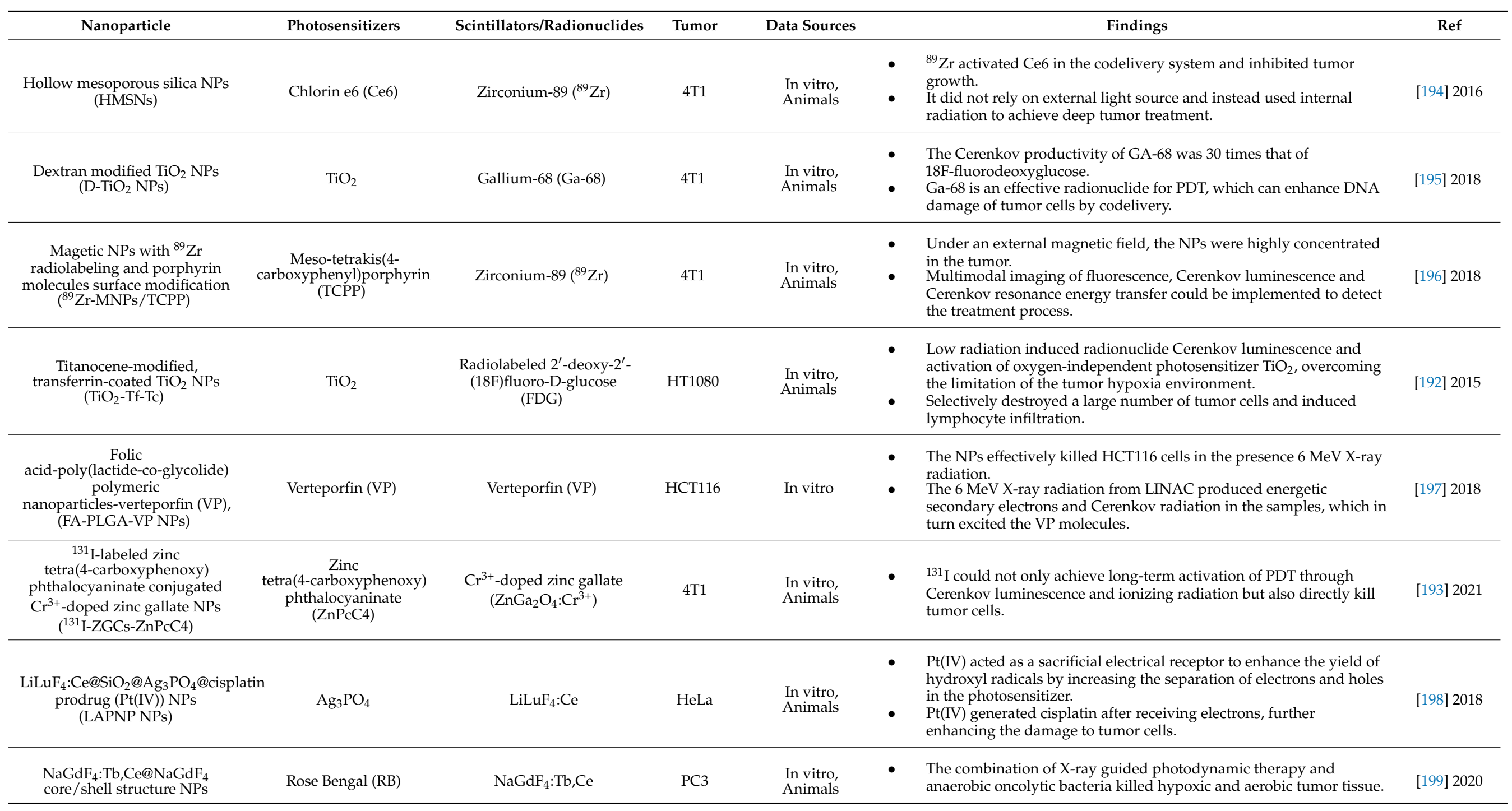




\subsection{Sonodynamic Therapy (SDT)}

Sonodynamic therapy (SDT) uses ultrasound and acoustic sensitizers to treat cancer. Ultrasound, on the one hand, activates ultrasonic-sensitive species gathered in tumor cells through transient sonoluminescence to produce ROS. Hot spots from ultrasonic radiation, on the other hand, release energy high enough to cause bubbles to form and oscillate, resulting in permanent cell damage. The latter phenomenon is also defined as sonographyinduced cavitation effects that together lead to tumor cell apoptosis or necrosis [200-203]. The extent of tumor cell death depends on the intensity and frequency of ultrasound and the duration of exposure, so it is controllable, safe and noninvasive, similar to PDT.

The strong penetration ability and low tissue attenuation of ultrasound make sonophotodynamic therapy (SPDT) have a wider range of indications. PDT is suitable for superficial cancer types such as skin cancer [204] and esophageal cancer [205], but the treatment effect for melanoma skin cancer has not been ideal, which is caused by the absorption of visible light by melanin to remove ROS [206]. In contrast, SDT was significantly more effective for melanoma than PDT, although there was no differences between the two treatments for common skin cancer [207].

The ultrasonic activation ability of PSs has also been verified to some extent. Some PSs have both SPDT activity, which are referred to as photoacoustic agents. We only need to use a specific wavelength of light and a specific frequency of sound to activate the photoacoustic agent so that the photoacoustic combination can be achieved without considering the coordination of physical and chemical properties in the process of multidrug combination. Currently, porphyrins as well as Ce6, Photolon ${ }^{\mathrm{TM}} /$ Fotolon $^{\mathrm{TM}}$, and Sonoflora 1 Sonnelux-1 have been verified [208-210]; several studies have reported their therapeutic efficacy and safety, and there are many potential PSs whose ultrasonic activation ability is being verified, which will also find applications in photoacoustic combination in the near future [211].

The modification of codelivery vectors helps to achieve multifunctional and integrated photoacoustic therapy with high spatial activation and preferential treatment of deep penetration. Hong L et al. [68] prepared Ce6 and the high oxygen carrying capacity carrier perfluoropolyether into a nanoemulsion and tested the ROS generation ability at different tissue depths after the application of ultrasound or light. The results showed that PDT had a high degree of spatial selectivity for surface and endoscopically accessible areas, which made it more suitable for the treatment of tumors in vital organs, such as brain cancer. SDT, on the other hand, had the same ROS production efficiency for tissues at different depths. SPDT was conducive to targeting different depths and meeting specific spatial accuracy requirements. Accordingly, sensitive drugs can be combined with tissueengineered scaffolds to kill tumor cells after surgery. The results showed that SPDT had fewer toxic side effects than conventional chemotherapy, so it has great potential [212]. More examples of recently published studies on the codelivery of photosensitizers and sonophotosensitizers based on nanocarriers are illustrated in Table 7. 
Table 7. Codelivery of photosensitizers and sonophotosensitizers based on nanocarriers.

\begin{tabular}{|c|c|c|c|c|c|c|}
\hline Nanoparticle & Photosensitizers & Sonophotosensitizers & Tumor & Data Sources & Findings & Ref \\
\hline $\begin{array}{l}\text { Glypican-3-targeted, } \\
\text { curcumin-loaded microbubbles } \\
\text { (GPC3-CUR-MBs) }\end{array}$ & Curcumin (CUR) & Curcumin (CUR) & HepG2 & In vitro, Animals & $\begin{array}{l}\text { The combined therapy sonophotodynamic therapy (SPDT) } \\
\text { had more obvious antitumor effects than SDT or PDT alone. }\end{array}$ & [213] 2020 \\
\hline $\begin{array}{c}\text { Curcumin-loaded } \\
\text { poly(L-lactic-co-glycolic acid) } \\
\text { microbubbles } \\
\text { (CUR-PLGA-MBs) }\end{array}$ & Curcumin (CUR) & Curcumin (CUR) & HepG2 & In vitro & $\begin{array}{l}\text { - Mitochondrial membrane potential loss was induced by } \\
\text { increased reactive oxygen species (ROS) generation, leading } \\
\text { to tumor cell apoptosis and thermal decay. }\end{array}$ & [214] 2020 \\
\hline
\end{tabular}




\subsection{Multidrug Codelivery}

Cumbersome drug delivery processes, limited efficiency, slow release and low efficacy are common characteristics of multidrug codelivery. Therefore, the main research direction is still focused on solving the problem of coloading and controlled release.

Chen Y [70] designed an NIR-sensitive nanocomposite DLA-UCNPs@SiO ${ }_{2}-\mathrm{C} / \mathrm{HA} @$ $\mathrm{mSiO}_{2}$-DOX@NB. This complex breaks the chemical bond and releases paclitaxel (PTX) when irradiated by NIR light at $980 \mathrm{~nm}$, which is then activated by visible light at $450-480 \mathrm{~nm}$ to exert synergistic photodynamic and photothermal therapeutic effects. Similarly, the $\mathrm{Fe}_{3} \mathrm{O}_{4} / \mathrm{g}-\mathrm{C}_{3} \mathrm{~N}_{4} @ P$ Py-DOX nanocomposite prepared by Cheng HL [4] and graphitelike carbon oxide $\left(\mathrm{G}-\mathrm{C}_{3} \mathrm{~N}_{4}\right)$ can not only generate $\mathrm{O}_{2}$ through photocatalytic degradation to improve the hypoxic state of solid tumors but also enable the loading of PTX into its mesoporous structure. Polypyrrole, as a photothermal agent, was shown to enhance the antitumor effect of chemo-PDT.

CuS NPs with both PTT and PDT activities were used to achieve the triple combination of PTT-PDT-HT [216]. Curcio A [217] prepared a maghemite $\left(\gamma-\mathrm{Fe}_{2} \mathrm{O}_{3}\right)$ nanoflower-like multicore nanoparticle conceived for $\mathrm{MH}$ and coated it with a spiky copper sulfide shell (IONF@CuS) for PTT and PDT. This combination showed a good therapeutic effect and reduced the dose of maghemite, which meant lower toxicity. Simultaneous activation of PDT and PTT by X-ray radiation-induced scintillator luminescence can be triply magnified when combined with radiotherapy. Luo L [218] conjugated a scintillator complex and a gold nanorod nanosensitizer. Lanthanide complexes can provide excellent luminescence under X-ray excitation, while gold nanorods can be used not only as PSs for PTT but also as radiosensitizers for enhanced radiotherapy due to their strong near-infrared light and X-ray absorption capacity. As expected, the group treated with both laser and X-ray irradiation showed the best synergistic effect, with significantly more effective tumor ablation than that in the other monotherapy groups.

Low-dose docetaxel has been reported to mediate ICD-activated immune effects [219], and this function of PDT is also mentioned above. Therefore, folic acid-modified mesoporous CuS NPs coloaded with DOX, polyethylenimide-PpIX (PEI-PpIX) and CPG for the treatment of cold tumor breast cancer can effectively rebuild the tumor microenvironment and promote the invasion of cytotoxic T lymphocytes (CTLs) [220]. In addition, it was reported that a MOF was used to integrate chemotherapy-phototherapy-photothermoimmunotherapy. Cus PpIX and DOX were loaded into the core and shell of the metalorganic skeleton ZIF-8, respectively, while CPG was adsorbed outside the shell. This design effectively realized the organic unification of antitumor and antirecurrence/metastasis [221]. More examples of recently published studies on the codelivery of multidrugs based on nanocarriers are illustrated in Table 8. 
Table 8. Codelivery of multidrugs based on nanocarriers.

\section{Nanoparticle}

Type of Combination Therapy

Data Sources

Findings

- As a cosolvent, HAS improved the water solubility of the photosensitizer and dispersed it sufficiently to reduce the aggregation quenching effect.
Human serum

albumin-paclitaxel-sinoporphyri sodium nanotheranostics (HAS-PTX-DVDMS)
Photodynamic

therapy/Chemotherapy/Sonodynamic $\quad 4 \mathrm{~T} 1 \quad$ In vitro, Animals therapy
- It could be used as fluorescent probe, with stronger fluorescence imaging ability and ${ }^{1} \mathrm{O}_{2}$ generation ability than that of DVDMS alone.

- The addition of ultrasound increased the tumor cell mortality rate from $70 \%$ to $90 \%$, and the effect of triple therapy was superior $\mathrm{ZrO}_{2}$-coated, doxorubicin hydrochloride-,
chlorin e6- and tetradecanol-loaded upconversion NPs

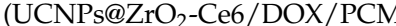

Photodynamic therapy/Chemotherapy/Hyperthermia
In vitro, Animals

- It could be used to realize multimodal imaging guidance (MRI, CT and UCL) in conjunction with tumor therapy.

- Under near-infrared light, the heat generated by UCNPs helped to kill cancer cells and dissolve PCM, triggering the release of drug and the production of ROS, resulting in an effective integration of photothermal/photodynamic therapy with chemotherapy.

TF-mediated endocytosis enhanced accumulation and retention in

tumor cells.
Effective near-infrared light was converted to heat while

Iron-dependent artesunate-loaded, insferrin-modified, hollow mesopor
Photodynamic therapy/Photothermal therapy/Chemotherapy

MCF-7

In vitro, Animals producing high levels of ROS for PDT.
- Under near-infrared laser radiation, the NPs produced a strong photothermal effect, which induced controlled release of DOX

1-Tetradecanol-, doxorubicin- and chlorin e6-loaded hollow mesoporous copper (HPDC) NPs)
Photodynamic therapy/Photothermal therapy/Chemotherapy
In vitro, Animals and Ce6

- The NPs presented low systemic toxicity and good blood compatibility and were able to eradicate breast cancer in $4 \mathrm{~T} 1$ mice. sulfide NPs (H-CuS@PCM/DOX/Ce6

- Wrapping NPs in cancer cell membranes imparted unique advantages such as immune escape and homologous
(Enaminitrile molecule gel encapsulating doxorubicin core/Mesoporous ion-doped upconversion shell) NPs wrapped with a cancer cell membran silica-coated, CuS-loaded, lanthanide
Photodynamic therapy/Photothermal therapy/Chemotherapy
MCF-7,

$4 \mathrm{~T} 1$ binding ability.

Through the transformation of near-infrared energy into ultraviolet light from the UCNP nucleus, enaminitrile molecule phase transition was stimulated to generate ROS for PDT, thus avoiding the limited penetration of ultraviolet light to tissues. 
Table 8. Cont.

\begin{tabular}{|c|c|c|c|c|c|}
\hline Nanoparticle & Type of Combination Therapy & Tumor & Data Sources & Findings & Ref \\
\hline $\begin{array}{l}\text { (Upconversion core/chlorin e6, } \\
\text { doxorubicin hydrochloride coloaded } \\
\text { mesoporous silica shell) NPs conjugated } \\
\text { with polyethylene glycol-modified } \\
\text { graphene (DOX-UMCG) }\end{array}$ & $\begin{array}{l}\text { Photodynamic therapy/Photothermal } \\
\text { therapy/Chemotherapy }\end{array}$ & HeLa & In vitro, Animals & $\begin{array}{l}\text { Only low-intensity near-infrared light was required to produce a } \\
\text { domino effect, avoiding the phototoxicity of high-intensity } \\
\text { exposure to nearby healthy cells. } \\
\text { Synergistic Chemo/PTT/PDT anticancer effect with low systemic } \\
\text { toxicity. }\end{array}$ & [227] 2020 \\
\hline $\begin{array}{l}\text { Thiol-terminated monomethoxyl } \\
\text { poly(ethylene glycol) and } \\
\text { mercaptoropionylhydrazide-modified } \\
\text { gold nanorods covalently conjugated } \\
\text { with 5-aminolevulinic acid and } \\
\text { doxorubicin (GNRs-MPH-ALA/DOX_PEG) }\end{array}$ & $\begin{array}{l}\text { Photodynamic therapy/Photothermal } \\
\text { therapy/Chemotherapy }\end{array}$ & MCF-7 & In vitro, Animals & $\begin{array}{l}\text { - Combined CT/PDT/PTT therapy killed McF-7 cells more } \\
\text { effectively, with superadditive antitumor effects and no obvious } \\
\text { systemic toxicity. } \\
\text { The circulating half-life of GNRs-MPH-ALA/DOX_PEG in blood } \\
\text { was approximately } 52 \mathrm{~min} \text {, and the tumor aggregation rate } \\
\text { was 3.3\%. }\end{array}$ & [228] 2018 \\
\hline $\begin{array}{l}\text { Folic acid-functionalized, } \\
\text { paclitaxel-loaded MgAl layered double } \\
\text { hydroxide gated mesoporous silica NPs } \\
\text { (MT@L-PTX@FA) }\end{array}$ & $\begin{array}{l}\text { Photodynamic therapy/Photothermal } \\
\text { therapy/Chemotherapy }\end{array}$ & HepG2 & In vitro & $\begin{array}{l}\text { - Under near-infrared irradiation, the NPs effectively converted } \\
\text { photon energy into ROS and heat, enhancing toxicity to } \\
\text { tumor cells. } \\
\text { It presented obvious slow-release characteristics and was sensitive } \\
\text { to } \mathrm{pH} \text {. It could dissolve } \mathrm{MgAl} \mathrm{LDH} \text { into } \mathrm{Mg}^{2+} \text { and } \mathrm{Al}^{3+} \text { under the } \\
\text { low } \mathrm{pH} \text { of the tumor site, selectively releasing PTX for } \\
\text { chemotherapy. }\end{array}$ & [229] 2019 \\
\hline $\begin{array}{c}\text { Folic } \\
\text { acid-CuS/docetaxel@polyethylenimine- } \\
\text { protoporphyrin IX-CPG } \\
\text { (FA-CuS/DTX@PEI-PpIXCpG) }\end{array}$ & $\begin{array}{l}\text { Photodynamic therapy/Photothermal } \\
\text { therapy/Chemotherapy/Immunotherapy }\end{array}$ & $4 \mathrm{~T} 1$ & In vitro, Animals & $\begin{array}{l}\text { - FA-CD@PP-CpG medium and low-dose DTX promoted CTL } \\
\text { infiltration, improved the efficacy of anti-PD-L1 antibody } \\
\text { (APD-L1), inhibited MDSCs, and effectively polarized MDSCs to } \\
\text { the M1 phenotype. }\end{array}$ & [220] 2019 \\
\hline
\end{tabular}




\section{Outlook and Discussion}

Complex microenvironments, abnormal growth rates and drug resistance during treatment make cancer treatment difficult. PDT, as a new treatment scheme, has the advantages of simple operation, noninvasiveness, safety and few side effects. The emergence of nano-carriers has made great contributions to the development of photodynamic therapy, and the limitation of physical and chemical properties of PS in PDT was solved. In addition to therapeutic effects, PS-mediated fluorescence can also be used for optical imaging to detect tumors, or as image guidance for surgery [230]. The major issues contributing to the failure of PDT are metastatic tumor at unknown sites, inadequate light delivery and lack of sufficient oxygen. This limitation can be addressed by multidrug combination. The combination of PDT and other treatment schemes, such as chemotherapy and radiotherapy, immunotherapy, gene therapy and PTT, has obvious advantages over the single application of one treatment scheme. With the development of nanodelivery vectors, codelivery has become a common method of multidrug combination. In this paper, we review the research progress of PDT combined with other therapies to improve the therapeutic effect on tumors based on the codelivery of nanodelivery carriers.

The combination of PDT and chemotherapy can significantly reduce the dose of chemotherapy drugs, overcome the deep-seated tumors that PDT cannot kill by multidrug resistant chemotherapy, and increase the level of ROS in the tumor microenvironment to enhance the sensitivity of cancer cells to PDT. In combination with immunotherapy, the PDT-mediated inflammatory response and ICD activate the body's immune response, which can be further enhanced by codelivering an immune adjuvant CPG or tumor antigen, providing a reconstructed immune microenvironment for tumor immunotherapy. PDT can be codelivered with therapeutic genes that target the regulation of hypoxia, angiogenesis, and heat shock proteins, alleviating the tolerance of long-term PDT therapy. Combined with therapeutic genes that target the regulation of other key proteins in tumor growth and metabolism, multimechanism antitumor effects can be achieved. The combination of PDT and PTT can synergistically increase the oxidative stress response at the tumor site, and the PTT-mediated increase in reactive oxygen species levels at the tumor site enhances the sensitivity of tumor cells to PDT. Studies on the combination of PDT and HT are still scarce. Although the discovery of $\mathrm{MH}$ is of great help to this codelivery strategy, more studies are still needed to confirm any synergistic effects. PDT combined with radiotherapy can overcome the limitation of PDT in light and can significantly improve the therapeutic effect of PDT on deep tumors. Combined sonodynamic therapy is beneficial to achieve accurate treatment, while satisfying different depths and is suitable for tumor treatment of fine organs. Multidrug codelivery can realize the organic unity of antitumor and antimetastatic effects, as well as recurrence through different antitumor mechanisms.

Although these different antitumor combinations have shown good results, they have their own limitations. PDT has been reported many times to induce sustained systemic immunosuppression, but the current mechanism has not been clarified. The speculated reasons are as follows: (1) ROS produced during PDT inactivate DAMPs released by apoptotic tumor cells, thus failing to stimulate immunity; and (2) apoptotic tumor cells release IL-10, TGF-beta and other immunosuppressive cytokines that affect the generation of $\mathrm{CD} 8+\mathrm{T}$ cells [231]. This immunosuppression will affect not only the subsequent treatment effect of PDT but also the combination of PDT and immunotherapy. The combination of PDT and PTT is dependent on laser irradiation, which has a poor effect on deep tumors. The combination of PDT and radiotherapy is also subject to the strong oxygen dependence of PDT. Multidrug combination delivery is limited by the development of delivery vectors, drug loading and release. These problems are one of the reasons why codelivery systems based on nanocarriers have not been applied in clinical applications, while other reasons include incomplete safety assessment of the preparation protocol and difficulty in large-scale clinical applications of the preparation. 
In summary, this paper focuses on the synergistic enhancement of antitumor therapeutic effects by codelivery combinations of PDT and different treatment regimens. This type of approach is definitely a potential therapeutic strategy, and the existing problems mentioned above need more research to resolve.

Author Contributions: Y.-L.Y. and K.L. conceived the concept of the review article, and prepared the content outline. Y.-L.Y. and K.L. contributed to the review writing for different sections. L.Y. supervised the writing and final revision of the manuscript. All authors have read and agreed to the published version of the manuscript.

Funding: This research received no external funding.

Institutional Review Board Statement: Not applicable.

Informed Consent Statement: Not applicable.

Data Availability Statement: Not applicable.

Conflicts of Interest: The authors declare no conflict of interest.

\section{Abbreviations}

PDT photodynamic therapy

PTT photothermal therapy

HT hyperthermia therapy

MT magnetic hyperthermia therapy

MNPs magnetic nanoparticles

AMF alternating magnetic field

ROS reactive oxygen

ICD immunogenic cell death

PFC perfluorocarbon

CS chitosan

NPs nanoparticles

OVA ovalbumin

DOX doxorubicin

PS photosensitisers

PoP Porphyrin-phospholipid

Qu quercetin

Pt platinum

CRT calreticulin

DAMPs damage-associated molecular patterns

TLR toll-like receptor

APC antigen-presenting cell

nMOF nano-metal organic framework

TME tumor microenvironment

PEG polyethylene glycol

PLGA poly(lactide-co-glycolic)

GO graphene oxide

PpIX protoporphyrin IX

PTX paclitaxel

SDT sonodynamic therapy

SPDT sono-photodynamic therapy

IgG immunoglobulin $\mathrm{G}$

HIF1 $\alpha$ hypoxia-inducible factor $\alpha$

VEGF vascular growth factor

PCI photochemical Internalization

IDO1 indoleamine 2, 3-dioxygenase 1

CLTA-4 cytotoxic T-lymphocyte-associated antigen 4

PD-L1 programmed death-ligand 1

Ce6 chlorin e6 


$\begin{array}{ll}\text { PEI } & \text { polythylenimide } \\ \text { ERP } & \text { enhanced permeability and retention effects } \\ \text { XPDT } & \text { X-ray photodynamic therapy } \\ \text { LDL } & \begin{array}{l}\text { low-density lipoprotein } \\ \text { 1MT }\end{array} \\ \text { dextro-1-methyltryptophan } \\ \text { LCP } & \text { lipid-calcium-phosphate } \\ \text { EMT } & \text { epithelial mesenchymal transition } \\ \text { HPD } & \text { hematoporphyrin } \\ \text { MB } & \text { methylene blue } \\ \text { NIR } & \text { near infrared } \\ \text { ZnPc } & \text { zinc phthalocyanine } \\ \text { ZnF16Pc } & \text { zinc hexadecafluorophthalocyanine } \\ \text { ClAlPc } & \text { aluminum chloride phthalocyanine } \\ \text { HYP } & \text { hypericin } \\ \text { LAHP } & \text { linoleic acid peroxide } \\ \text { CRT } & \text { calreticulin } \\ \text { AXT } & \text { axitinib } \\ \text { 5-ALA } & \text { 5-aminolevulinic acid } \\ \text { PAH } & \text { polyacrylamide } \\ \text { PAA } & \text { polyacrylic acid } \\ \mathrm{H}_{2} \text { TCPP } & \text { tetrakis (4-carboxyphenyl) porphyrin } \\ \text { RNP } & \text { ribonucleoprotein } \\ \text { EGFR } & \text { epidermal growth factor receptor } \\ \text { HER-2 } & \text { human epidermal growth factor receptor 2 } \\ \text { TfR } & \text { transferrin receptor } \\ \text { PIN } & \text { photoimmune nanoconjugated platform }\end{array}$

\section{References}

1. Kumar, A.; Moralès, O.; Mordon, S.; Delhem, N.; Boleslawski, E. Could Photodynamic Therapy Be a Promising Therapeutic Modality in Hepatocellular Carcinoma Patients? A Critical Review of Experimental and Clinical Studies. Cancers 2021, $13,5176$. [CrossRef]

2. Donohoe, C.; Senge, M.O.; Arnaut, L.G.; Gomes-da-Silva, L.C. Cell death in photodynamic therapy: From oxidative stress to anti-tumor immunity. Biochim. Biophys. Acta Rev. Cancer 2019, 1872, 188308. [CrossRef]

3. Wachowska, M.; Muchowicz, A.; Demkow, U. Immunological aspects of antitumor photodynamic therapy outcome. Central-Eur. J. Immunol. 2015, 40, 481-485. [CrossRef]

4. Kwiatkowski, S.; Knap, B.; Przystupski, D.; Saczko, J.; Kedzierska, E.; Knap-Czop, K.; Kotlinska, J.; Michel, O.; Kotowski, K.; Kulbacka, J. Photodynamic therapy-mechanisms, photosensitizers and combinations. Biomed. Pharmacother. 2018, 106, $1098-1107$. [CrossRef] [PubMed]

5. Liu, H.; Hu, Y.; Sun, Y.; Wan, C.; Zhang, Z.; Dai, X.; Lin, Z.; He, Q.; Yang, Z.; Huang, P.; et al. Co-delivery of Bee Venom Melittin and a Photosensitizer with an Organic-Inorganic Hybrid Nanocarrier for Photodynamic Therapy and Immunotherapy. ACS Nano 2019, 13, 12638-12652. [CrossRef]

6. Tardivo, J.P.; Del Giglio, A.; de Oliveira, C.S.; Gabrielli, D.S.; Junqueira, H.C.; Tada, D.B.; Severino, D.; de Fatima Turchiello, R.; Baptista, M.S. Methylene blue in photodynamic therapy: From basic mechanisms to clinical applications. Photodiagn. Photodyn. Ther. 2005, 2, 175-191. [CrossRef]

7. Junqueira, H.C.; Severino, D.; Dias, L.G.; Gugliotti, M.S.; Baptista, M.S. Modulation of methylene blue photochemical properties based on adsorption at aqueous micelle interfaces. Phys. Chem. Chem. Phys. 2002, 4, 2320-2328. [CrossRef]

8. Ma, M.; Cheng, L.; Zhao, A.; Zhang, H.; Zhang, A. Pluronic-based graphene oxide-methylene blue nanocomposite for photodynamic/photothermal combined therapy of cancer cells. Photodiagn. Photodyn. Ther. 2020, 29, 101640. [CrossRef]

9. Vallejo, M.C.S.; Moura, N.M.M.; Ferreira Faustino, M.A.; Almeida, A.; Gonçalves, I.; Serra, V.V.; Neves, M.G.P.M.S. An Insight into the Role of Non-Porphyrinoid Photosensitizers for Skin Wound Healing. Int. J. Mol. Sci. 2020, 22, 234. [CrossRef] [PubMed]

10. Vallejo, M.C.S.; Moura, N.M.M.; Gomes, A.T.P.C.; Joaquinito, A.S.M.; Faustino, M.A.F.; Almeida, A.; Goncalves, I.; Serra, V.V.; Neves, M.G.P.M.S. The Role of Porphyrinoid Photosensitizers for Skin Wound Healing. Int. J. Mol. Sci. 2021, 22, 4121. [CrossRef] [PubMed]

11. Rahmanian, N.; Eskandani, M.; Barar, J.; Omidi, Y. Recent trends in targeted therapy of cancer using graphene oxide-modified multifunctional nanomedicines. J. Drug Target. 2017, 25, 202-215. [CrossRef] [PubMed]

12. Kang, M.S.; Lee, S.Y.; Kim, K.S.; Han, D.W. State of the Art Biocompatible Gold Nanoparticles for Cancer Theragnosis. Pharmaceutics 2020, 12, 701. [CrossRef] 
13. Bekmukhametova, A.; Ruprai, H.; Hook, J.M.; Mawad, D.; Houang, J.; Lauto, A. Photodynamic therapy with nanoparticles to combat microbial infection and resistance. Nanoscale 2020, 12, 21034-21059. [CrossRef] [PubMed]

14. Qin, L.; Jiang, S.; He, H.; Ling, G.; Zhang, P. Functional black phosphorus nanosheets for cancer therapy. J. Control Release 2020, 318, 50-66. [CrossRef] [PubMed]

15. Huang, Y.Y.; Sharma, S.K.; Yin, R.; Agrawal, T.; Chiang, L.Y.; Hamblin, M.R. Functionalized fullerenes in photodynamic therapy. J. Biomed. Nanotechnol. 2014, 10, 1918-1936. [CrossRef]

16. Liu, C.; Qin, H.; Kang, L.; Chen, Z.; Wang, H.; Qiu, H.; Ren, J.; Qu, X. Graphitic carbon nitride nanosheets as a multifunctional nanoplatform for photochemical internalization-enhanced photodynamic therapy. J. Mater. Chem. B 2018, 6, 7908-7915. [CrossRef]

17. Kessel, D. Photodynamic Therapy: A Brief History. J. Clin. Med. 2019, 8, 1581. [CrossRef]

18. Lin, C.; Zhang, Y.; Wang, J.; Sui, A.; Xiu, L.; Zhu, X. The study of effect and mechanism of 630-nm laser on human lung adenocarcinoma cell xenograft model in nude mice mediated by hematoporphyrin derivatives. Lasers Med. Sci. 2020, 35, 1085-1094. [CrossRef]

19. Dougherty, T.J.; Lawrence, G.; Kaufman, J.H.; Boyle, D.; Weishaupt, K.R.; Goldfarb, A. Photoradiation in the treatment of recurrent breast carcinoma. J. Natl. Cancer Inst. 1979, 62, 231-237. [PubMed]

20. Gunaydin, G.; Gedik, M.E.; Ayan, S. Photodynamic Therapy-Current Limitations and Novel Approaches. Front. Chem. 2021, 9, 691697. [CrossRef] [PubMed]

21. Liang, H.; Zhou, Z.; Luo, R.; Sang, M.; Liu, B.; Sun, M.; Qu, W.; Feng, F.; Liu, W. Tumor-specific activated photodynamic therapy with an oxidation-regulated strategy for enhancing anti-tumor efficacy. Theranostics 2018, 8, 5059-5071. [CrossRef]

22. Ormond, A.B.; Freeman, H.S. Dye Sensitizers for Photodynamic Therapy. Materials 2013, 6, 817-840. [CrossRef] [PubMed]

23. Jeong, Y.I.; Cha, B.; Lee, H.L.; Song, Y.H.; Jung, Y.H.; Kwak, T.W.; Choi, C.; Jeong, G.W.; Nah, J.W.; Kang, D.H. Simple nanophotosensitizer fabrication using water-soluble chitosan for photodynamic therapy in gastrointestinal cancer cells. Int. J. Pharm. 2017, 532, 194-203. [CrossRef] [PubMed]

24. Son, J.; Yi, G.; Kwak, M.H.; Yang, S.M.; Park, J.M.; Lee, B.I.; Choi, M.G.; Koo, H. Gelatin-chlorin e6 conjugate for in vivo photodynamic therapy. J. Nanobiotechnol. 2019, 17, 50. [CrossRef]

25. Petrovic, L.Z.; Xavierselvan, M.; Kuriakose, M.; Kennedy, M.D.; Nguyen, C.D.; Batt, J.J.; Detels, K.B.; Mallidi, S. Mutual impact of clinically translatable near-infrared dyes on photoacoustic image contrast and in vitro photodynamic therapy efficacy. J. Biomed. Opt. 2020, 25, 063808.

26. Yan, L.; Luo, L.; Amirshaghaghi, A.; Miller, J.; Meng, C.; You, T.; Busch, T.M.; Tsourkas, A.; Cheng, Z. Dextran-Benzoporphyrin Derivative (BPD) Coated Superparamagnetic Iron Oxide Nanoparticle (SPION) Micelles for T2-Weighted Magnetic Resonance Imaging and Photodynamic Therapy. Bioconjug. Chem. 2019, 30, 2974-2981. [CrossRef]

27. Rizvi, I.; Nath, S.; Obaid, G.; Ruhi, M.K.; Moore, K.; Bano, S.; Kessel, D.; Hasan, T. A Combination of Visudyne and a Lipidanchored Liposomal Formulation of Benzoporphyrin Derivative Enhances Photodynamic Therapy Efficacy in a 3D Model for Ovarian Cancer. Photochem. Photobiol. 2019, 95, 419-429. [CrossRef]

28. Roguin, L.P.; Chiarante, N.; García Vior, M.C.; Marino, J. Zinc(II) phthalocyanines as photosensitizers for antitumor photodynamic therapy. Int. J. Biochem. Cell Biol. 2019, 114, 105575. [CrossRef]

29. Santos, K.L.M.; Barros, R.M.; da Silva Lima, D.P.; Nunes, A.M.A.; Sato, M.R.; Faccio, R.; de Lima Damasceno, B.P.G.; OshiroJunior, J.A. Prospective application of phthalocyanines in the photodynamic therapy against microorganisms and tumor cells: A mini-review. Photodiagn. Photodyn. Ther. 2020, 32, 102032. [CrossRef]

30. Lo, P.C.; Rodríguez-Morgade, M.S.; Pandey, R.K.; Ng, D.; Torres, T.; Dumoulin, F. The unique features and promises of phthalocyanines as advanced photosensitisers for photodynamic therapy of cancer. Chem. Soc. Rev. 2020, 49, $1041-1056$. [CrossRef]

31. Oleinick, N.L.; Morris, R.L.; Belichenko, I. The role of apoptosis in response to photodynamic therapy: What, where, why, and how. Photochem. Photobiol. Sci. 2002, 1, 1-21.

32. Buytaert, E.; Dewaele, M.; Agostinis, P. Molecular effectors of multiple cell death pathways initiated by photodynamic therapy. Biochim. Biophys. Acta 2007, 1776, 86-107. [CrossRef] [PubMed]

33. Buytaert, E.; Callewaert, G.; Hendrickx, N.; Scorrano, L.; Hartmann, D.; Missiaen, L.; Vandenheede, J.R.; Heirman, I.; Grooten, J.; Agostinis, P. Role of endoplasmic reticulum depletion and multidomain proapoptotic BAX and BAK proteins in shaping cell death after hypericin-mediated photodynamic therapy. FASEB J. 2006, 20, 756-758. [CrossRef] [PubMed]

34. Owens, E.A.; Henary, M.; El Fakhri, G.; Choi, H.S. Tissue-Specific Near-Infrared Fluorescence Imaging. Acc. Chem. Res. 2016, 49, 1731-1740. [CrossRef]

35. Duse, L.; Agel, M.R.; Pinnapireddy, S.R.; Schafer, J.; Selo, M.A.; Ehrhardt, C.; Bakowsky, U. Photodynamic Therapy of Ovarian Carcinoma Cells with Curcumin-Loaded Biodegradable Polymeric Nanoparticles. Pharmaceutics 2019, 11, 282. [CrossRef]

36. Machado, F.C.; Adum de Matos, R.P.; Primo, F.L.; Tedesco, A.C.; Rahal, P.; Calmon, M.F. Effect of curcumin-nanoemulsion associated with photodynamic therapy in breast adenocarcinoma cell line. Bioorg. Med. Chem. 2019, 27, 1882-1890. [CrossRef]

37. de Morais, F.A.P.; Goncalves, R.S.; Vilsinski, B.H.; Lazarin-Bidoia, D.; Balbinot, R.B.; Tsubone, T.M.; Brunaldi, K.; Nakamura, C.V.; Hioka, N.; Caetano, W. Hypericin photodynamic activity in DPPC liposomes-part II: Stability and application in melanoma B16-F10 cancer cells. Photochem. Photobiol. Sci. 2020, 19, 620-630. [CrossRef] 
38. Liu, Y.; Ma, K.; Jiao, T.; Xing, R.; Shen, G.; Yan, X. Water-Insoluble Photosensitizer Nanocolloids Stabilized by Supramolecular Interfacial Assembly towards Photodynamic Therapy. Sci. Rep. 2017, 7, 42978. [CrossRef] [PubMed]

39. Amanda Pedroso de Morais, F.; Sonchini Goncalves, R.; Souza Campanholi, K.; Martins de Franca, B.; Augusto Capeloto, O.; Lazarin-Bidoia, D.; Bento Balbinot, R.; Vataru Nakamura, C.; Carlos Malacarne, L.; Caetano, W.; et al. Photophysical characterization of Hypericin-loaded in micellar, liposomal and copolymer-lipid nanostructures based F127 and DPPC liposomes. Spectrochim. Acta A Mol. Biomol. Spectrosc. 2021, 248, 119173. [CrossRef]

40. Wu, P.T.; Lin, C.L.; Lin, C.W.; Chang, N.C.; Tsai, W.B.; Yu, J. Methylene-Blue-Encapsulated Liposomes as Photodynamic Therapy Nano Agents for Breast Cancer Cells. Nanomaterials 2018, 9, 14. [CrossRef]

41. Khanal, A.; Bui, M.P.; Seo, S.S. Microgel-encapsulated methylene blue for the treatment of breast cancer cells by photodynamic therapy. J. Breast Cancer 2014, 17, 18-24. [CrossRef]

42. Zheng, Y.; Li, Z.; Chen, H.; Gao, Y. Nanoparticle-based drug delivery systems for controllable photodynamic cancer therapy. Eur. J. Pharm. Sci. 2020, 144, 105213. [CrossRef]

43. Huang, Y.; Wang, T.; Tan, Q.; He, D.; Wu, M.; Fan, J.; Yang, J.; Zhong, C.; Li, K.; Zhang, J. Smart Stimuli-Responsive and Mitochondria Targeting Delivery in Cancer Therapy. Int. J. Nanomed. 2021, 16, 4117-4146. [CrossRef] [PubMed]

44. Biswas, S.; Torchilin, V.P. Nanopreparations for organelle-specific delivery in cancer. Adv. Drug Deliv. Rev. 2014, 66, 26-41. [CrossRef]

45. Liu, C.; Li, Y.; Li, Y.; Duan, Q. Preparation of a star-shaped copolymer with porphyrin core and four PNIPAM-b-POEGMA arms for photodynamic therapy. Mater. Sci. Eng. C Mater. Biol. Appl. 2019, 98, 74-82. [CrossRef]

46. Weishaupt, K.R.; Gomer, C.J.; Dougherty, T.J. Identification of singlet oxygen as the cytotoxic agent in photoinactivation of a murine tumor. Cancer Res. 1976, 36, 2326-2329. [PubMed]

47. Dabrzalska, M.; Janaszewska, A.; Zablocka, M.; Mignani, S.; Majoral, J.P.; Klajnert-Maculewicz, B. Complexing Methylene Blue with Phosphorus Dendrimers to Increase Photodynamic Activity. Molecules 2017, 22, 345. [CrossRef] [PubMed]

48. Wang, P.; Tang, H.; Zhang, P. Plasmonic Nanoparticle-based Hybrid Photosensitizers with Broadened Excitation Profile for Photodynamic Therapy of Cancer Cells. Sci. Rep. 2016, 6, 34981. [CrossRef]

49. Liang, R.; Liu, L.; He, H.; Chen, Z.; Han, Z.; Luo, Z.; Wu, Z.; Zheng, M.; Ma, Y.; Cai, L. Oxygen-boosted immunogenic photodynamic therapy with gold nanocages@manganese dioxide to inhibit tumor growth and metastases. Biomaterials 2018, 177, 149-160. [CrossRef] [PubMed]

50. Zhang, C.; Cheng, X.; Chen, M.; Sheng, J.; Ren, J.; Jiang, Z.; Cai, J.; Hu, Y. Fluorescence guided photothermal/photodynamic ablation of tumours using pH-responsive chlorin e6-conjugated gold nanorods. Colloids Surf. B Biointerfaces 2017, 160, 345-354 [CrossRef]

51. Amanda Pedroso de Morais, F.; Sonchini Gonçalves, R.; Souza Campanholi, K.; Martins de França, B.; Augusto Capeloto, O.; Lazarin-Bidoia, D.; Bento Balbinot, R.; Vataru Nakamura, C.; Carlos Malacarne, L.; Caetano, W.; et al. Nanographene oxide-methylene blue as phototherapies platform for breast tumor ablation and metastasis prevention in a syngeneic orthotopic murine model. J. Nanobiotechnol. 2018, 16,9.

52. Shi, X.; Zhan, Q.; Yan, X.; Zhou, J.; Zhou, L.; Wei, S. Oxyhemoglobin nano-recruiter preparation and its application in biomimetic red blood cells to relieve tumor hypoxia and enhance photodynamic therapy activity. J. Mater. Chem. B 2020, 8, 534-545. [CrossRef]

53. Luo, Z.; Tian, H.; Liu, L.; Chen, Z.; Liang, R.; Chen, Z.; Wu, Z.; Ma, A.; Zheng, M.; Cai, L. Tumor-targeted hybrid protein oxygen carrier to simultaneously enhance hypoxia-dampened chemotherapy and photodynamic therapy at a single dose. Theranostics 2018, 8, 3584-3596. [CrossRef] [PubMed]

54. Fang, H.; Gai, Y.; Wang, S.; Liu, Q.; Zhang, X.; Ye, M.; Tan, J.; Long, Y.; Wang, K.; Zhang, Y.; et al. Biomimetic oxygen delivery nanoparticles for enhancing photodynamic therapy in triple-negative breast cancer. J. Nanobiotechnol. 2021, 19, 81. [CrossRef]

55. Zhou, Z.; Song, J.; Tian, R.; Yang, Z.; Yu, G.; Lin, L.; Zhang, G.; Fan, W.; Zhang, F.; Niu, G.; et al. Activatable Singlet Oxygen Generation from Lipid Hydroperoxide Nanoparticles for Cancer Therapy. Angew. Chem. Int. Ed. Engl. 2017, 56, 6492-6496. [CrossRef]

56. Hu, D.; Chen, L.; Qu, Y.; Peng, J.; Chu, B.; Shi, K.; Hao, Y.; Zhong, L.; Wang, M.; Qian, Z. Oxygen-generating Hybrid Polymeric Nanoparticles with Encapsulated Doxorubicin and Chlorin e6 for Trimodal Imaging-Guided Combined Chemo-Photodynamic Therapy. Theranostics 2018, 8, 1558-1574. [CrossRef] [PubMed]

57. Usacheva, M.; Swaminathan, S.K.; Kirtane, A.R.; Panyam, J. Enhanced photodynamic therapy and effective elimination of cancer stem cells using surfactant-polymer nanoparticles. Mol. Pharm. 2014, 11, 3186-3195. [CrossRef]

58. Yue, D.; Cai, X.; Fan, M.; Zhu, J.; Tian, J.; Wu, L.; Jiang, Q.; Gu, Z. An Alternating Irradiation Strategy-Driven Combination Therapy of PDT and RNAi for Highly Efficient Inhibition of Tumor Growth and Metastasis. Adv. Healthc. Mater. 2021, 10, e2001850. [CrossRef] [PubMed]

59. Girotti, A.W.; Fahey, J.M.; Korytowski, W. Multiple Means by Which Nitric Oxide can Antagonize Photodynamic Therapy. Curr. Med. Chem. 2016, 23, 2754-2769. [CrossRef]

60. Girotti, A.W.; Fahey, J.M.; Korytowski, W. Upregulation of nitric oxide in tumor cells as a negative adaptation to photodynamic therapy. Lasers Surg. Med. 2018, 50, 590-598. [CrossRef]

61. Fahey, J.M.; Girotti, A.W. Nitric oxide-mediated resistance to photodynamic therapy in a human breast tumor xenograft model: Improved outcome with $\mathrm{NOS}_{2}$ inhibitors. Nitric Oxide 2017, 62, 52-61. [CrossRef] 
62. Carter, K.A.; Luo, D.; Razi, A.; Geng, J.; Shao, S.; Ortega, J.; Lovell, J.F. Sphingomyelin Liposomes Containing Porphyrinphospholipid for Irinotecan Chemophototherapy. Theranostics 2016, 6, 2329-2336. [CrossRef]

63. Cramer, G.M.; Moon, E.K.; Cengel, K.A.; Busch, T.M. Photodynamic Therapy and Immune Checkpoint Blockadet. Photochem. Photobiol. 2020, 96, 954-961. [CrossRef]

64. El-Daly, S.M.; Abba, M.L.; Gamal-Eldeen, A.M. The role of microRNAs in photodynamic therapy of cancer. Eur. J. Med. Chem. 2017, 142, 550-555. [CrossRef]

65. Liu, X.; Yang, G.; Zhang, L.; Liu, Z.; Cheng, Z.; Zhu, X. Photosensitizer cross-linked nano-micelle platform for multimodal imaging guided synergistic photothermal/photodynamic therapy. Nanoscale 2016, 8, 15323-15339. [CrossRef] [PubMed]

66. Gu, H.; Xu, K.; Yang, Z.; Chang, C.K.; Xu, B. Synthesis and cellular uptake of porphyrin decorated iron oxide nanoparticles-a potential candidate for bimodal anticancer therapy. Chem. Commun. 2005, 4270-4272. [CrossRef] [PubMed]

67. Popovich, K.; Procházková, L.; Pelikánová, I.T.; Vlk, M.; Palkovský, M.; Jarý, V.; Nikl, M.; Múčka, V.; Mihóková, E.; Čuba, V. Preliminary study on singlet oxygen production using $\mathrm{CeF}_{3}: \mathrm{Tb}_{3}+\mathrm{SiO}_{2}-\mathrm{PpIX}$. Radiat. Meas. 2016, 90, 325-328. [CrossRef]

68. Hong, L.; Pliss, A.M.; Zhan, Y.; Zheng, W.; Xia, J.; Liu, L.; Qu, J.; Prasad, P.N. Perfluoropolyether Nanoemulsion Encapsulating Chlorin e6 for Sonodynamic and Photodynamic Therapy of Hypoxic Tumor. Nanomaterials 2020, 10, 2058. [CrossRef]

69. Yu, Y.; Zhang, Z.; Wang, Y.; Zhu, H.; Li, F.; Shen, Y.; Guo, S. A new NIR-triggered doxorubicin and photosensitizer indocyanine green co-delivery system for enhanced multidrug resistant cancer treatment through simultaneous chemo/photothermal/photodynamic therapy. Acta Biomater. 2017, 59, 170-180. [CrossRef]

70. Chen, Y.; Zhang, F.; Wang, Q.; Tong, R.; Lin, H.; Qu, F. Near-infrared light-mediated LA-UCNPs@SiO $2-C / \mathrm{HA}_{2} \mathrm{mSiO} 2-\mathrm{DOX} @ N B$ nanocomposite for chemotherapy/PDT/PTT and imaging. Dalton Trans. 2017, 46, 14293-14300. [CrossRef] [PubMed]

71. Cheng, H.L.; Guo, H.L.; Xie, A.J.; Shen, Y.H.; Zhu, M.Z. 4-in-1 $\mathrm{Fe}_{3} \mathrm{O}_{4} /$ g- $\mathrm{C}_{3} \mathrm{~N}_{4} @ P P y-D O X$ nanocomposites: Magnetic targeting guided trimode combinatorial chemotherapy/PDT/PTT for cancer. J. Inorg. Biochem. 2021, 215, 111329. [CrossRef]

72. Bukowski, K.; Kciuk, M.; Kontek, R. Mechanisms of Multidrug Resistance in Cancer Chemotherapy. Int. J. Mol. Sci. 2020, 21, 3233. [CrossRef] [PubMed]

73. Qin, S.Y.; Cheng, Y.J.; Lei, Q.; Zhang, A.Q.; Zhang, X.Z. Combinational strategy for high-performance cancer chemotherapy. Biomaterials 2018, 171, 178-197. [CrossRef]

74. Chistiakov, D.A.; Myasoedova, V.A.; Orekhov, A.N.; Bobryshev, Y.V. Nanocarriers in Improving Chemotherapy of Multidrug Resistant Tumors: Key Developments and Perspectives. Curr. Pharm. Des. 2017, 23, 3301-3308. [CrossRef] [PubMed]

75. Srinivas, U.S.; Tan, B.W.Q.; Vellayappan, B.A.; Jeyasekharan, A.D. ROS and the DNA damage response in cancer. Redox Biol. 2019, 25, 101084. [CrossRef] [PubMed]

76. Yang, H.; Villani, R.M.; Wang, H.; Simpson, M.J.; Roberts, M.S.; Tang, M.; Liang, X. The role of cellular reactive oxygen species in cancer chemotherapy. J. Exp. Clin. Cancer Res. 2018, 37, 266. [CrossRef]

77. Schreiber, S.; Gross, S.; Brandis, A.; Harmelin, A.; Rosenbach-Belkin, V.; Scherz, A.; Salomon, Y. Local photodynamic therapy (PDT) of rat C6 glioma xenografts with Pd-bacteriopheophorbide leads to decreased metastases and increase of animal cure compared with surgery. Int. J. Cancer 2002, 99, 279-285. [CrossRef]

78. Luo, D.; Carter, K.A.; Miranda, D.; Lovell, J.F. Chemophototherapy: An Emerging Treatment Option for Solid Tumors. Adv. Sci. 2017, 4, 1600106. [CrossRef]

79. Lila, A.S.; Ishida, T.; Kiwada, H. Targeting anticancer drugs to tumor vasculature using cationic liposomes. Pharm. Res. 2010, 27, 1171-1183. [CrossRef]

80. Luo, D.; Li, N.; Carter, K.A.; Lin, C.; Geng, J.; Shao, S.; Huang, W.C.; Qin, Y.; Atilla-Gokcumen, G.E.; Lovell, J.F. Rapid LightTriggered Drug Release in Liposomes Containing Small Amounts of Unsaturated and Porphyrin-Phospholipids. Small 2016, 12, 3039-3047. [CrossRef]

81. Miranda, D.; Lovell, J.F. Mechanisms of Light-induced Liposome Permeabilization. Bioeng. Transl. Med. 2016, 1, 267-276. [CrossRef]

82. Luo, D.; Geng, J.; Li, N.; Carter, K.A.; Shao, S.; Atilla-Gokcumen, G.E.; Lovell, J.F. Vessel-Targeted Chemophototherapy with Cationic Porphyrin-Phospholipid Liposomes. Mol. Cancer Ther. 2017, 16, 2452-2461. [CrossRef]

83. Luo, D.; Carter, K.A.; Molins, E.A.G.; Straubinger, N.L.; Geng, J.; Shao, S.; Jusko, W.J.; Straubinger, R.M.; Lovell, J.F. Pharmacokinetics and pharmacodynamics of liposomal chemophototherapy with short drug-light intervals. J. Control Release 2019, 297, 39-47. [CrossRef]

84. Luo, D.; Carter, K.A.; Razi, A.; Geng, J.; Shao, S.; Giraldo, D.; Sunar, U.; Ortega, J.; Lovell, J.F. Doxorubicin encapsulated in stealth liposomes conferred with light-triggered drug release. Biomaterials 2016, 75, 193-202. [CrossRef]

85. Luo, D.; Goel, S.; Liu, H.J.; Carter, K.A.; Jiang, D.; Geng, J.; Kutyreff, C.J.; Engle, J.W.; Huang, W.C.; Shao, S.; et al. Intrabilayer (64)Cu Labeling of Photoactivatable, Doxorubicin-Loaded Stealth Liposomes. ACS Nano 2017, 11, 12482-12491. [CrossRef] [PubMed]

86. Luo, D.; Carter, K.A.; Geng, J.; He, X.; Lovell, J.F. Short Drug-Light Intervals Improve Liposomal Chemophototherapy in Mice Bearing MIA PaCa-2 Xenografts. Mol. Pharm. 2018, 15, 3682-3689. [CrossRef]

87. Jiang, W.; Delahunty, I.M.; Xie, J. Oxygenating the way for enhanced chemophototherapy. Theranostics 2018, 8, 3870-3871. [CrossRef] [PubMed]

88. Sunil, V.; Mozhi, A.; Zhan, W.; Teoh, J.H.; Wang, C.H. Convection enhanced delivery of light responsive antigen capturing oxygen generators for chemo-phototherapy triggered adaptive immunity. Biomaterials 2021, 275, 120974. [CrossRef] 
89. Liu, X.L.; Dong, X.; Yang, S.C.; Lai, X.; Liu, H.J.; Gao, Y.; Feng, H.Y.; Zhu, M.H.; Yuan, Y.; Lu, Q.; et al. Biomimetic Liposomal Nanoplatinum for Targeted Cancer Chemophototherapy. Adv. Sci. 2021, 8, 2003679. [CrossRef] [PubMed]

90. Tian, H.; Zhang, J.; Zhang, H.; Jiang, Y.; Song, A.; Luan, Y. Low side-effect and heat-shock protein-inhibited chemo-phototherapy nanoplatform via co-assembling strategy of biotin-tailored IR780 and quercetin. Chem. Eng. J. 2020, 382, 123043. [CrossRef]

91. He, C.; Duan, X.; Guo, N.; Chan, C.; Poon, C.; Weichselbaum, R.R.; Lin, W. Core-shell nanoscale coordination polymers combine chemotherapy and photodynamic therapy to potentiate checkpoint blockade cancer immunotherapy. Nat. Commun. 2016, 7, 12499. [CrossRef]

92. Zhang, X.; Wu, M.; Li, J.; Lan, S.; Zeng, Y.; Liu, X.; Liu, J. Light-Enhanced Hypoxia-Response of Conjugated Polymer Nanocarrier for Successive Synergistic Photodynamic and Chemo-Therapy. ACS Appl. Mater. Interfaces 2018, 10, 21909-21919. [CrossRef] [PubMed]

93. Mao, B.; Liu, C.; Zheng, W.; Li, X.; Ge, R.; Shen, H.; Guo, X.; Lian, Q.; Shen, X.; Li, C. Cyclic cRGDfk peptide and Chlorin e6 functionalized silk fibroin nanoparticles for targeted drug delivery and photodynamic therapy. Biomaterials 2018, 161, 306-320. [CrossRef]

94. Zhang, J.; Huang, H.; Xue, L.; Zhong, L.; Ge, W.; Song, X.; Zhao, Y.; Wang, W.; Dong, X. On-demand drug release nanoplatform based on fluorinated aza-BODIPY for imaging-guided chemo-phototherapy. Biomaterials 2020, 256, 120211. [CrossRef] [PubMed]

95. Zong, J.; Peng, H.; Qing, X.; Fan, Z.; Xu, W.; Du, X.; Shi, R.; Zhang, Y. pH-Responsive Pluronic F127-Lenvatinib-Encapsulated Halogenated Boron-Dipyrromethene Nanoparticles for Combined Photodynamic Therapy and Chemotherapy of Liver Cancer. ACS Omega 2021, 6, 12331-12342. [CrossRef]

96. Cheng, X.; He, L.; Xu, J.; Fang, Q.; Yang, L.; Xue, Y.; Wang, X.; Tang, R. Oxygen-producing catalase-based prodrug nanoparticles overcoming resistance in hypoxia-mediated chemo-photodynamic therapy. Acta Biomater. 2020, 112, 234-249. [CrossRef]

97. Sun, B.; Chen, Y.; Yu, H.; Wang, C.; Zhang, X.; Zhao, H.; Chen, Q.; He, Z.; Luo, C.; Sun, J. Photodynamic PEG-coated ROS-sensitive prodrug nanoassemblies for core-shell synergistic chemo-photodynamic therapy. Acta Biomater. 2019, 92, 219-228. [CrossRef] [PubMed]

98. Tan, P.; Cai, H.; Wei, Q.; Tang, X.; Zhang, Q.; Kopytynski, M.; Yang, J.; Yi, Y.; Zhang, H.; Gong, Q.; et al. Enhanced chemophotodynamic therapy of an enzyme-responsive prodrug in bladder cancer patient-derived xenograft models. Biomaterials 2021, 277, 121061. [CrossRef]

99. Shu, M.; Tang, J.; Chen, L.; Zeng, Q.; Li, C.; Xiao, S.; Jiang, Z.; Liu, J. Tumor microenvironment triple-responsive nanoparticles enable enhanced tumor penetration and synergetic chemo-photodynamic therapy. Biomaterials 2021, 268, 120574. [CrossRef] [PubMed]

100. Zhong, D.; Wu, H.; Wu, Y.; Li, Y.; Yang, J.; Gong, Q.; Luo, K.; Gu, Z. Redox dual-responsive dendrimeric nanoparticles for mutually synergistic chemo-photodynamic therapy to overcome drug resistance. J. Control Release 2021, 329, 1210-1221. [CrossRef] [PubMed]

101. Yi, X.; Hu, J.J.; Dai, J.; Lou, X.; Zhao, Z.; Xia, F.; Tang, B.Z. Self-Guiding Polymeric Prodrug Micelles with Two AggregationInduced Emission Photosensitizers for Enhanced Chemo-Photodynamic Therapy. ACS Nano 2021, 15, 3026-3037. [CrossRef] [PubMed]

102. Naldini, L. Gene therapy returns to centre stage. Nature 2015, 526, 351-360. [CrossRef]

103. Xin, Y.; Huang, M.; Guo, W.W.; Huang, Q.; Zhang, L.Z.; Jiang, G. Nano-based delivery of RNAi in cancer therapy. Mol. Cancer 2017, 16, 134. [CrossRef]

104. Vaughan, H.J.; Green, J.J.; Tzeng, S.Y. Cancer-Targeting Nanoparticles for Combinatorial Nucleic Acid Delivery. Adv. Mater. 2020, 32, e1901081. [CrossRef] [PubMed]

105. Goodman, A.M.; Hogan, N.J.; Gottheim, S.; Li, C.; Clare, S.E.; Halas, N.J. Understanding Resonant Light-Triggered DNA Release from Plasmonic Nanoparticles. ACS Nano 2017, 11, 171-179. [CrossRef]

106. Matsushita-Ishiodori, Y.; Ohtsuki, T. Photoinduced RNA interference. Acc. Chem. Res. 2012, 45, 1039-1047. [CrossRef] [PubMed]

107. Wang, J.; He, H.; Xu, X.; Wang, X.; Chen, Y.; Yin, L. Far-red light-mediated programmable anti-cancer gene delivery in cooperation with photodynamic therapy. Biomaterials 2018, 171, 72-82. [CrossRef]

108. Chen, L.; Chen, C.; Chen, W.; Li, K.; Chen, X.; Tang, X.; Xie, G.; Luo, X.; Wang, X.; Liang, H.; et al. Biodegradable Black Phosphorus Nanosheets Mediate Specific Delivery of hTERT siRNA for Synergistic Cancer Therapy. ACS Appl. Mater. Interfaces 2018, 10, 21137-21148. [CrossRef]

109. Vaupel, P.; Kallinowski, F.; Okunieff, P. Blood flow, oxygen and nutrient supply, and metabolic microenvironment of human tumors: A review. Cancer Res. 1989, 49, 6449-6465.

110. Chen, W.H.; Lecaros, R.L.; Tseng, Y.C.; Huang, L.; Hsu, Y.C. Nanoparticle delivery of HIF1 $\alpha$ siRNA combined with photodynamic therapy as a potential treatment strategy for head-and-neck cancer. Cancer Lett. 2015, 359, 65-74. [CrossRef]

111. Deng, S.; Li, X.; Liu, S.; Chen, J.; Li, M.; Chew, S.Y.; Leong, K.W.; Cheng, D. Codelivery of CRISPR-Cas9 and chlorin e6 for spatially controlled tumor-specific gene editing with synergistic drug effects. Sci. Adv. 2020, 6, eabb4005. [CrossRef]

112. Jang, Y.; Kim, D.; Lee, H.; Jang, H.; Park, S.; Kim, G.E.; Lee, H.J.; Kim, H.J.; Kim, H. Development of an ultrasound triggered nanomedicine-microbubble complex for chemo-photodynamic-gene therapy. Nanomedicine 2020, 27, 102194. [CrossRef] [PubMed]

113. Cao, Y.; Meng, X.; Wang, D.; Zhang, K.; Dai, W.; Dong, H.; Zhang, X. Intelligent $\mathrm{MnO}_{2} / \mathrm{Cu}_{2-x} \mathrm{~S}$ for Multimode Imaging Diagnostic and Advanced Single-Laser Irradiated Photothermal/Photodynamic Therapy. ACS Appl. Mater. Interfaces 2018, 10, 17732-17741. [CrossRef] [PubMed] 
114. Yang, C.; Fu, Y.; Huang, C.; Hu, D.; Zhou, K.; Hao, Y.; Chu, B.; Yang, Y.; Qian, Z. Chlorin e6 and CRISPR-Cas9 dual-loading system with deep penetration for a synergistic tumoral photodynamic-immunotherapy. Biomaterials 2020, 255, 120194. [CrossRef] [PubMed]

115. Ma, C.; Shi, L.; Huang, Y.; Shen, L.; Peng, H.; Zhu, X.; Zhou, G. Nanoparticle delivery of Wnt-1 siRNA enhances photodynamic therapy by inhibiting epithelial-mesenchymal transition for oral cancer. Biomater. Sci. 2017, 28, 494-501. [CrossRef]

116. Liu, S.Y.; Xu, Y.; Yang, H.; Liu, L.; Zhao, M.; Yin, W.; Xu, Y.T.; Huang, Y.; Tan, C.; Dai, Z.; et al. Ultrathin 2D Copper(I) 1,2,4Triazolate Coordination Polymer Nanosheets for Efficient and Selective Gene Silencing and Photodynamic Therapy. Adv. Mater. 2021, 33, e2100849. [CrossRef]

117. Laroui, N.; Coste, M.; Lichon, L.; Bessin, Y.; Gary-Bobo, M.; Pratviel, G.; Bonduelle, C.; Bettache, N.; Ulrich, S. Combination of photodynamic therapy and gene silencing achieved through the hierarchical self-assembly of porphyrin-siRNA complexes. Int. J. Pharm. 2019, 659, 118585. [CrossRef]

118. Liu, Y.; Pan, Y.; Cao, W.; Xia, F.; Liu, B.; Niu, J.; Alfranca, G.; Sun, X.; Ma, L.; de la Fuente, J.M.; et al. A tumor microenvironment responsive biodegradable $\mathrm{CaCO}_{3} / \mathrm{MnO}_{2}$-based nanoplatform for the enhanced photodynamic therapy and improved PD-L1 immunotherapy. Theranostics 2019, 9, 6867-6884. [CrossRef]

119. Zhao, R.; Liang, X.; Zhao, B.; Chen, M.; Liu, R.; Sun, S.; Yue, X.; Wang, S. Ultrasound assisted gene and photodynamic synergistic therapy with multifunctional FOXA1-siRNA loaded porphyrin microbubbles for enhancing therapeutic efficacy for breast cancer. Biomaterials 2018, 173, 58-70. [CrossRef]

120. Jin, Y.; Wang, H.; Li, X.; Zhu, H.; Sun, D.; Sun, X.; Liu, H.; Zhang, Z.; Cao, L.; Gao, C.; et al. Multifunctional DNA Polymer-Assisted Upconversion Therapeutic Nanoplatform for Enhanced Photodynamic Therapy. ACS Appl. Mater. Interfaces 2020, 12, 26832-26841. [CrossRef]

121. Lichon, L.; Kotras, C.; Myrzakhmetov, B.; Arnoux, P.; Daurat, M.; Nguyen, C.; Durand, D.; Bouchmella, K.; Ali, L.M.A.; Durand, J.O.; et al. Polythiophenes with Cationic Phosphonium Groups as Vectors for Imaging, siRNA Delivery, and Photodynamic Therapy. Nanomaterials 2020, 10, 1432. [CrossRef] [PubMed]

122. Zheng, N.; Luo, X.; Zhang, Z.; Wang, A.; Song, W. Cationic Polyporphyrins as siRNA Delivery Vectors for Photodynamic and Gene Synergistic Anticancer Therapy. ACS Appl. Mater. Interfaces 2021, 13, 27513-27521. [CrossRef] [PubMed]

123. Mezghrani, B.; Ali, L.M.A.; Richeter, S.; Durand, J.O.; Hesemann, P.; Bettache, N. Periodic Mesoporous Ionosilica Nanoparticles for Green Light Photodynamic Therapy and Photochemical Internalization of siRNA. ACS Appl. Mater. Interfaces 2021, 13, 29325-29339. [CrossRef]

124. Nath, S.; Obaid, G.; Hasan, T. The Course of Immune Stimulation by Photodynamic Therapy: Bridging Fundamentals of Photochemically Induced Immunogenic Cell Death to the Enrichment of T-Cell Repertoire. Photochem. Photobiol. 2019, 95, 1288-1305. [CrossRef]

125. Banstola, A.; Jeong, J.H.; Yook, S. Immunoadjuvants for cancer immunotherapy: A review of recent developments. Acta Biomater. 2020, 114, 16-30. [CrossRef]

126. Lu, K.; Aung, T.; Guo, N.; Weichselbaum, R.; Lin, W. Nanoscale Metal-Organic Frameworks for Therapeutic, Imaging, and Sensing Applications. Adv. Mater. 2018, 30, e1707634. [CrossRef]

127. Cai, Z.; Xin, F.; Wei, Z.; Wu, M.; Lin, X.; Du, X.; Chen, G.; Zhang, D.; Zhang, Z.; Liu, X.; et al. Photodynamic Therapy Combined with Antihypoxic Signaling and CpG Adjuvant as an In Situ Tumor Vaccine Based on Metal-Organic Framework Nanoparticles to Boost Cancer Immunotherapy. Adv. Healthc. Mater. 2020, 9, e1900996. [CrossRef] [PubMed]

128. Ni, K.; Luo, T.; Lan, G.; Culbert, A.; Song, Y.; Wu, T.; Jiang, X.; Lin, W. A Nanoscale Metal-Organic Framework to Mediate Photodynamic Therapy and Deliver CpG Oligodeoxynucleotides to Enhance Antigen Presentation and Cancer Immunotherapy. Angew. Chem. Int. Ed. Engl. 2020, 59, 1108-1112. [CrossRef]

129. Xia, Y.; Gupta, G.K.; Castano, A.P.; Mroz, P.; Avci, P.; Hamblin, M.R. CpG oligodeoxynucleotide as immune adjuvant enhances photodynamic therapy response in murine metastatic breast cancer. J. Biophotonics 2014, 7, 897-905. [CrossRef]

130. Huang, R.; Ding, Z.; Jiang, B.P.; Luo, Z.; Chen, T.; Guo, Z.; Ji, S.C.; Liang, H.; Shen, X.C. Artificial Metalloprotein Nanoanalogues: In Situ Catalytic Production of Oxygen to Enhance Photoimmunotherapeutic Inhibition of Primary and Abscopal Tumor Growth. Small 2020, 16, e2004345. [CrossRef]

131. Ding, B.; Shao, S.; Yu, C.; Teng, B.; Wang, M.; Cheng, Z.; Wong, K.L.; Ma, P.; Lin, J. Large-Pore Mesoporous-Silica-Coated Upconversion Nanoparticles as Multifunctional Immunoadjuvants with Ultrahigh Photosensitizer and Antigen Loading Efficiency for Improved Cancer Photodynamic Immunotherapy. Adv. Mater. 2018, 30, e1802479. [CrossRef]

132. Xu, C.; Nam, J.; Hong, H.; Xu, Y.; Moon, J.J. Positron Emission Tomography-Guided Photodynamic Therapy with Biodegradable Mesoporous Silica Nanoparticles for Personalized Cancer Immunotherapy. ACS Nano 2019, 13, 12148-12161. [CrossRef]

133. Pardoll, D.M. The blockade of immune checkpoints in cancer immunotherapy. Nat. Rev. Cancer 2012, 12, 252-264. [CrossRef]

134. Yang, X.; Zhang, W.; Jiang, W.; Kumar, A.; Zhou, S.; Cao, Z.; Zhan, S.; Yang, W.; Liu, R.; Teng, Y.; et al. Nanoconjugates to enhance PDT-mediated cancer immunotherapy by targeting the indoleamine-2,3-dioxygenase pathway. J. Nanobiotechnol. 2021, 19, 182. [CrossRef]

135. Zhou, Y.; Ren, X.; Hou, Z.; Wang, N.; Jiang, Y.; Luan, Y. Engineering a photosensitizer nanoplatform for amplified photodynamic immunotherapy via tumor microenvironment modulation. Nanoscale Horiz. 2021, 6, 120-131. [CrossRef] [PubMed] 
136. Xu, J.; Yu, S.; Wang, X.; Qian, Y.; Wu, W.; Zhang, S.; Zheng, B.; Wei, G.; Gao, S.; Cao, Z.; et al. High Affinity of Chlorin e6 to Immunoglobulin $\mathrm{G}$ for Intraoperative Fluorescence Image-Guided Cancer Photodynamic and Checkpoint Blockade Therapy. ACS Nano 2019, 13, 10242-10260. [CrossRef] [PubMed]

137. Chen, S.X.; Ma, M.; Xue, F.; Shen, S.; Chen, Q.; Kuang, Y.; Liang, K.; Wang, X.; Chen, H. Construction of microneedle-assisted co-delivery platform and its combining photodynamic/immunotherapy. J. Control Release 2020, 324, 218-227. [CrossRef] [PubMed]

138. Wu, C.; Wang, L.; Tian, Y.; Guan, X.; Liu, Q.; Li, S.; Qin, X.; Yang, H.; Liu, Y. “Triple-Punch” Anticancer Strategy Mediated by Near-Infrared Photosensitizer/CpG Oligonucleotides Dual-Dressed and Mitochondria-Targeted Nanographene. ACS Appl. Mater. Interfaces 2018, 10, 6942-6955. [CrossRef]

139. Li, W.; Yang, J.; Luo, L.; Jiang, M.; Qin, B.; Yin, H.; Zhu, C.; Yuan, X.; Zhang, J.; Luo, Z.; et al. Targeting photodynamic and photothermal therapy to the endoplasmic reticulum enhances immunogenic cancer cell death. Nat. Commun. 2019, 10, 3349. [CrossRef]

140. Obaid, G.; Bano, S.; Mallidi, S.; Broekgaarden, M.; Kuriakose, J.; Silber, Z.; Bulin, A.L.; Wang, Y.; Mai, Z.; Jin, W.; et al. Impacting Pancreatic Cancer Therapy in Heterotypic in Vitro Organoids and in Vivo Tumors with Specificity-Tuned, NIR-Activable Photoimmunonanoconjugates: Towards Conquering Desmoplasia? Nano Lett. 2019, 19, 7573-7587. [CrossRef]

141. Bano, S.; Obaid, G.; Swain, J.W.R.; Yamada, M.; Pogue, B.W.; Wang, K.; Hasan, T. NIR Photodynamic Destruction of PDAC and HNSCC Nodules Using Triple-Receptor-Targeted Photoimmuno-Nanoconjugates: Targeting Heterogeneity in Cancer. J. Clin. Med. 2020, 9, 2390. [CrossRef]

142. Xia, F.; Hou, W.; Liu, Y.; Wang, W.; Han, Y.; Yang, M.; Zhi, X.; Li, C.; Qi, D.; Li, T.; et al. Cytokine induced killer cells-assisted delivery of chlorin e6 mediated self-assembled gold nanoclusters to tumors for imaging and immuno-photodynamic therapy. Biomaterials 2018, 170, 1-11. [CrossRef] [PubMed]

143. Liu, Y.; Yang, J.; Liu, B.; Cao, W.; Zhang, J.; Yang, Y.; Ma, L.; de la Fuente, J.M.; Song, J.; Ni, J.; et al. Human iPS Cells Loaded with $\mathrm{MnO}_{2}$-Based Nanoprobes for Photodynamic and Simultaneous Enhanced Immunotherapy Against Cancer. Nano-Micro Lett. 2020, 12, 127. [CrossRef] [PubMed]

144. Xu, J.; Xu, L.; Wang, C.; Yang, R.; Zhuang, Q.; Han, X.; Dong, Z.; Zhu, W.; Peng, R.; Liu, Z. Near-Infrared-Triggered Photodynamic Therapy with Multitasking Upconversion Nanoparticles in Combination with Checkpoint Blockade for Immunotherapy of Colorectal Cancer. ACS Nano 2017, 11, 4463-4474. [CrossRef]

145. Su, Z.; Xiao, Z.; Huang, J.; Wang, Y.; An, Y.; Xiao, H.; Peng, Y.; Pang, P.; Han, S.; Zhu, K.; et al. Dual-Sensitive PEG-Sheddable Nanodrug Hierarchically Incorporating PD-L1 Antibody and Zinc Phthalocyanine for Improved Immuno-Photodynamic Therapy. ACS Appl. Mater. Interfaces 2021, 13, 12845-12856. [CrossRef] [PubMed]

146. Li, X.; Kwon, N.; Guo, T.; Liu, Z.; Yoon, J. Innovative Strategies for Hypoxic-Tumor Photodynamic Therapy. Angew. Chem. Int. Ed. Engl. 2018, 57, 11522-11531. [CrossRef]

147. Gao, L.; Fei, J.; Zhao, J.; Li, H.; Cui, Y.; Li, J. Hypocrellin-loaded gold nanocages with high two-photon efficiency for photother$\mathrm{mal} /$ photodynamic cancer therapy in vitro. ACS Nano 2012, 6, 8030-8040. [CrossRef]

148. Tian, B.; Wang, C.; Zhang, S.; Feng, L.; Liu, Z. Photothermally enhanced photodynamic therapy delivered by nano-graphene oxide. ACS Nano 2011, 5, 7000-7009. [CrossRef]

149. Wang, S.; Riedinger, A.; Li, H.; Fu, C.; Liu, H.; Li, L.; Liu, T.; Tan, L.; Barthel, M.J.; Pugliese, G.; et al. Plasmonic copper sulfide nanocrystals exhibiting near-infrared photothermal and photodynamic therapeutic effects. ACS Nano 2015, 9, 1788-1800. [CrossRef]

150. Liu, X.; Su, H.; Shi, W.; Liu, Y.; Sun, Y.; Ge, D. Functionalized poly(pyrrole-3-carboxylic acid) nanoneedles for dual-imaging guided PDT/PTT combination therapy. Biomaterials 2018, 167, 177-190. [CrossRef]

151. Paszko, E.; Ehrhardt, C.; Senge, M.O.; Kelleher, D.P.; Reynolds, J.V. Nanodrug applications in photodynamic therapy. Photodiagn. Photodyn. Ther. 2011, 8, 14-29. [CrossRef]

152. Lin, J.; Wang, S.; Huang, P.; Wang, Z.; Chen, S.; Niu, G.; Li, W.; He, J.; Cui, D.; Lu, G.; et al. Photosensitizer-loaded gold vesicles with strong plasmonic coupling effect for imaging-guided photothermal/photodynamic therapy. ACS Nano 2013, 7, 5320-5329. [CrossRef]

153. Kalluru, P.; Vankayala, R.; Chiang, C.S.; Hwang, K.C. Nano-graphene oxide-mediated In vivo fluorescence imaging and bimodal photodynamic and photothermal destruction of tumors. Biomaterials 2016, 95, 1-10. [CrossRef] [PubMed]

154. Chen, B.; Cao, J.; Zhang, K.; Zhang, Y.N.; Lu, J.; Zubair Iqbal, M.; Zhang, Q.; Kong, X. Synergistic photodynamic and photothermal therapy of BODIPY-conjugated hyaluronic acid nanoparticles. J. Biomater. Sci. Polym. Ed. 2021, 32, 2028-2045. [CrossRef]

155. Wu, C.; Zhu, A.; Li, D.; Wang, L.; Yang, H.; Zeng, H.; Liu, Y. Photosensitizer-assembled PEGylated graphene-copper sulfide nanohybrids as a synergistic near-infrared phototherapeutic agent. Expert Opin. Drug Deliv. 2016, 13, 155-165. [CrossRef] [PubMed]

156. Bharathiraja, S.; Manivasagan, P.; Santha Moorthy, M.; Bui, N.Q.; Jang, B.; Phan, T.; Jung, W.K.; Kim, Y.M.; Lee, K.D.; Oh, J. Photo-based PDT/PTT dual model killing and imaging of cancer cells using phycocyanin-polypyrrole nanoparticles. Eur. J. Pharm. Biopharm. 2018, 123, 20-30. [CrossRef] [PubMed] 
157. Gao, C.; Dong, P.; Lin, Z.; Guo, X.; Jiang, B.P.; Ji, S.; Liang, H.; Shen, X.C. Near-Infrared Light Responsive Imaging-Guided Photothermal and Photodynamic Synergistic Therapy Nanoplatform Based on Carbon Nanohorns for Efficient Cancer Treatment. Chemistry 2018, 24, 12827-12837. [CrossRef]

158. Wu, J.; Williams, G.R.; Niu, S.; Yang, Y.; Li, Y.; Zhang, X.; Zhu, L.M. Biomineralized Bimetallic Oxide Nanotheranostics for Multimodal Imaging-Guided Combination Therapy. Theranostics 2020, 10, 841-855. [CrossRef]

159. Sun, Y.; Zhang, Y.; Gao, Y.; Wang, P.; He, G.; Blum, N.T.; Lin, J.; Liu, Q.; Wang, X.; Huang, P. Six Birds with One Stone: Versatile Nanoporphyrin for Single-Laser-Triggered Synergistic Phototheranostics and Robust Immune Activation. Adv. Mater. 2020, 32, e2004481. [CrossRef] [PubMed]

160. Jana, D.; Jia, S.; Bindra, A.K.; Xing, P.; Ding, D.; Zhao, Y. Clearable Black Phosphorus Nanoconjugate for Targeted Cancer Phototheranostics. ACS Appl. Mater. Interfaces 2020, 12, 18342-18351. [CrossRef]

161. Chen, S.; Huang, B.; Pei, W.; Wang, L.; Xu, Y.; Niu, C. Mitochondria-Targeting Oxygen-Sufficient Perfluorocarbon Nanoparticles for Imaging-Guided Tumor Phototherapy. Int. J. Nanomed. 2020, 15, 8641-8658. [CrossRef]

162. Li, P.; Liu, L.; Lu, Q.; Yang, S.; Yang, L.; Cheng, Y.; Wang, Y.; Wang, S.; Song, Y.; Tan, F.; et al. Ultrasmall MoS 2 Nanodots-Doped Biodegradable $\mathrm{SiO}_{2}$ Nanoparticles for Clearable FL/CT/MSOT Imaging-Guided PTT/PDT Combination Tumor Therapy. ACS Appl. Mater. Interfaces 2019, 11, 5771-5781. [CrossRef]

163. Shao, W.; Yang, C.; Li, F.; Wu, J.; Wang, N.; Ding, Q.; Gao, J.; Ling, D. Molecular Design of Conjugated Small Molecule Nanoparticles for Synergistically Enhanced PTT/PDT. Nano-Micro Lett. 2020, 12, 147. [CrossRef] [PubMed]

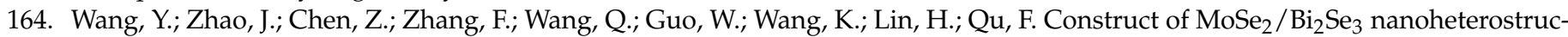
ture: Multimodal CT/PT imaging-guided PTT/PDT/chemotherapy for cancer treating. Biomaterials 2019, 217, 119282. [CrossRef] [PubMed]

165. Zhang, G.; Gou, H.; Liu, Y.; Xi, K.; Jiang, D.; Jia, X. pH-responsive PEG-chitosan/iron oxide hybrid nanoassemblies for low-power assisted PDT/PTT combination therapy. Nanomedicine 2020, 15, 1097-1112. [CrossRef]

166. Campu, A.; Focsan, M.; Lerouge, F.; Borlan, R.; Tie, L.; Rugina, D.; Astilean, S. ICG-loaded gold nano-bipyramids with NIR activatable dual PTT-PDT therapeutic potential in melanoma cells. Colloids Surf. B Biointerfaces 2020, 194, 111213. [CrossRef] [PubMed]

167. Yang, J.; Hou, M.; Sun, W.; Wu, Q.; Xu, J.; Xiong, L.; Chai, Y.; Liu, Y.; Yu, M.; Wang, H.; et al. Sequential PDT and PTT Using Dual-Modal Single-Walled Carbon Nanohorns Synergistically Promote Systemic Immune Responses against Tumor Metastasis and Relapse. Adv. Sci. 2020, 7, 2001088. [CrossRef]

168. Detty, M.R.; Gibson, S.L.; Wagner, S.J. Current clinical and preclinical photosensitizers for use in photodynamic therapy. J. Med. Chem. 2004, 47, 3897-3915. [CrossRef]

169. Streffer, C. Biological Basis of Thermotherapy (With Special Reference to Oncology). In Biological Basis of Oncologic Thermotherapy; Gautherie, M., Ed.; Springer: Berlin/Heidelberg, Germany, 1990; pp. 1-71.

170. Van Rhoon, G.C.; Franckena, M.; Ten Hagen, T.L. A moderate thermal dose is sufficient for effective free and TSL based thermochemotherapy. Adv. Drug Deliv. Rev. 2020, 163-164, 145-156. [CrossRef] [PubMed]

171. Jordan, A.; Scholz, R.; Wust, P.; Fahling, H.; Felix, R. Magnetic fluid hyperthermia (MFH): Cancer treatment with AC magnetic field induced excitation of biocompatible superparamagnetic nanoparticles. J. Magn. Magn. Mater. 1999, 201, 413-419. [CrossRef]

172. Huang, W.C.; Shen, M.Y.; Chen, H.H.; Lin, S.C.; Chiang, W.H.; Wu, P.H.; Chang, C.W.; Chiang, C.S.; Chiu, H.C. Monocytic delivery of therapeutic oxygen bubbles for dual-modality treatment of tumor hypoxia. J. Control Release 2015, 220, 738-750. [CrossRef]

173. Yanase, S.; Nomura, J.; Matsumura, Y.; Nagata, T.; Fujii, T.; Tagawa, T. Synergistic interaction of 5-aminolevulinic acid-based photodynamic therapy with simultaneous hyperthermia in an osteosarcoma tumor model. Int. J. Oncol. 2006, 29, 365-373. [CrossRef]

174. Wang, Z.; Zhang, F.; Shao, D.; Chang, Z.; Wang, L.; Hu, H.; Zheng, X.; Li, X.; Chen, F.; Tu, Z.; et al. Janus Nanobullets Combine Photodynamic Therapy and Magnetic Hyperthermia to Potentiate Synergetic Anti-Metastatic Immunotherapy. Adv. Sci. 2019, 6, 1901690. [CrossRef] [PubMed]

175. Di Corato, R.; Bealle, G.; Kolosnjaj-Tabi, J.; Espinosa, A.; Clement, O.; Silva, A.K.; Menager, C.; Wilhelm, C. Combining magnetic hyperthermia and photodynamic therapy for tumor ablation with photoresponsive magnetic liposomes. ACS Nano 2015, 9, 2904-2916. [CrossRef]

176. Pellosi, D.S.; Macaroff, P.P.; Morais, P.C.; Tedesco, A.C. Magneto low-density nanoemulsion (MLDE): A potential vehicle for combined hyperthermia and photodynamic therapy to treat cancer selectively. Mater. Sci. Eng. C 2018, 92, 103-111. [CrossRef] [PubMed]

177. Chen, W.; Zhang, J. Using nanoparticles to enable simultaneous radiation and photodynamic therapies for cancer treatment. J. Nanosci. Nanotechnol. 2006, 6, 1159-1166. [CrossRef]

178. Gadzhimagomedova, Z.; Zolotukhin, P.; Kit, O.; Kirsanova, D.; Soldatov, A. Nanocomposites for X-Ray Photodynamic Therapy. Int. J. Mol. Sci. 2020, 21, 4004. [CrossRef]

179. Hu, J.; Tang, Y.; Elmenoufy, A.H.; Xu, H.; Cheng, Z.; Yang, X. Nanocomposite-Based Photodynamic Therapy Strategies for Deep Tumor Treatment. Small 2015, 11, 5860-5887. [CrossRef]

180. Rimoldi, T.; Orsi, D.; Lagonegro, P.; Ghezzi, B.; Galli, C.; Rossi, F.; Salviati, G.; Cristofolini, L. CeF 3 -ZnO scintillating nanocomposite for self-lighted photodynamic therapy of cancer. J. Mater. Sci. Mater. Med. 2016, 27, 159. [CrossRef] [PubMed] 
181. Chen, M.H.; Jenh, Y.J.; Wu, S.K.; Chen, Y.S.; Hanagata, N.; Lin, F.H. Non-invasive Photodynamic Therapy in Brain Cancer by Use of $\mathrm{Tb}^{3+}$-Doped $\mathrm{LaF}_{3}$ Nanoparticles in Combination with Photosensitizer Through X-ray Irradiation: A Proof-of-Concept Study. Nanoscale Res. Lett. 2017, 12, 62. [CrossRef]

182. Yu, X.; Liu, X.; Wu, W.; Yang, K.; Mao, R.; Ahmad, F.; Chen, X.; Li, W. CT/MRI-Guided Synergistic Radiotherapy and X-ray Inducible Photodynamic Therapy Using Tb-Doped Gd-W-Nanoscintillators. Angew. Chem. Int. Ed. Engl. 2019, 58, 2017-2022. [CrossRef] [PubMed]

183. Kirakci, K.; Zelenka, J.; Rumlová, M.; Martinčík, J.; Nikl, M.; Ruml, T.; Lang, K. Octahedral molybdenum clusters as radiosensitizers for X-ray induced photodynamic therapy. J. Mater. Chem. B 2018, 6, 4301-4307. [CrossRef]

184. Rossi, F.; Bedogni, E.; Bigi, F.; Rimoldi, T.; Cristofolini, L.; Pinelli, S.; Alinovi, R.; Negri, M.; Dhanabalan, S.C.; Attolini, G.; et al. Porphyrin conjugated $\mathrm{SiC} / \mathrm{SiO}_{\mathrm{x}}$ nanowires for X-ray-excited photodynamic therapy. Sci. Rep. 2015, 5, 7606. [CrossRef]

185. Juzenas, P.; Chen, W.; Sun, Y.P.; Coelho, M.A.; Generalov, R.; Generalova, N.; Christensen, I.L. Quantum dots and nanoparticles for photodynamic and radiation therapies of cancer. Adv. Drug Deliv. Rev. 2008, 60, 1600-1614. [CrossRef]

186. Yuan, Q.; Wu, Y.; Wang, J.; Lu, D.; Zhao, Z.; Liu, T.; Zhang, X.; Tan, W. Targeted bioimaging and photodynamic therapy nanoplatform using an aptamer-guided G-quadruplex DNA carrier and near-infrared light. Angew. Chem. Int. Ed. Engl. 2013, 52, 13965-13969. [CrossRef]

187. Yu, Z.; Sun, Q.; Pan, W.; Li, N.; Tang, B. A Near-Infrared Triggered Nanophotosensitizer Inducing Domino Effect on Mitochondrial Reactive Oxygen Species Burst for Cancer Therapy. ACS Nano 2015, 9, 11064-11074. [CrossRef]

188. Dinakaran, D.; Sengupta, J.; Pink, D.; Raturi, A.; Chen, H.; Usmani, N.; Kumar, P.; Lewis, J.D.; Narain, R.; Moore, R.B. PEG-PLGA nanospheres loaded with nanoscintillators and photosensitizers for radiation-activated photodynamic therapy. Acta Biomater. 2020, 117, 335-348. [CrossRef] [PubMed]

189. Chen, H.; Wang, G.D.; Chuang, Y.J.; Zhen, Z.; Chen, X.; Biddinger, P.; Hao, Z.; Liu, F.; Shen, B.; Pan, Z.; et al. Nanoscintillatormediated X-ray inducible photodynamic therapy for in vivo cancer treatment. Nano Lett. 2015, 15, 2249-2256. [CrossRef]

190. Zhang, C.; Zhao, K.; Bu, W.; Ni, D.; Liu, Y.; Feng, J.; Shi, J. Marriage of scintillator and semiconductor for synchronous radiotherapy and deep photodynamic therapy with diminished oxygen dependence. Angew. Chem. Int. Ed. Engl. 2015, 54, 1770-1774. [CrossRef]

191. Chuang, Y.C.; Chu, C.H.; Cheng, S.H.; Liao, L.D.; Chu, T.S.; Chen, N.T.; Paldino, A.; Hsia, Y.; Chen, C.T.; Lo, L.W. Annealingmodulated nanoscintillators for nonconventional $X$-ray activation of comprehensive photodynamic effects in deep cancer theranostics. Theranostics 2020, 10, 6758-6773. [CrossRef]

192. Kotagiri, N.; Sudlow, G.P.; Akers, W.J.; Achilefu, S. Breaking the depth dependency of phototherapy with Cerenkov radiation and low-radiance-responsive nanophotosensitizers. Nat. Nanotechnol. 2015, 10, 370-379. [CrossRef]

193. Wang, Q.; Liu, N.; Hou, Z.; Shi, J.; Su, X.; Sun, X. Radioiodinated Persistent Luminescence Nanoplatform for Radiation-Induced Photodynamic Therapy and Radiotherapy. Adv. Healthc. Mater. 2021, 10, e2000802. [CrossRef]

194. Kamkaew, A.; Cheng, L.; Goel, S.; Valdovinos, H.F.; Barnhart, T.E.; Liu, Z.; Cai, W. Cerenkov Radiation Induced Photodynamic Therapy Using Chlorin e6-Loaded Hollow Mesoporous Silica Nanoparticles. ACS Appl. Mater. Interfaces 2016, 8, $26630-26637$. [CrossRef]

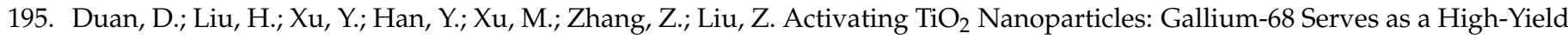
Photon Emitter for Cerenkov-Induced Photodynamic Therapy. ACS Appl. Mater. Interfaces 2018, 10, 5278-5286. [CrossRef]

196. Ni, D.; Ferreira, C.A.; Barnhart, T.E.; Quach, V.; Yu, B.; Jiang, D.; Wei, W.; Liu, H.; Engle, J.W.; Hu, P.; et al. Magnetic Targeting of Nanotheranostics Enhances Cerenkov Radiation-Induced Photodynamic Therapy. J. Am. Chem. Soc. 2018, 140, 14971-14979. [CrossRef]

197. Clement, S.; Chen, W.; Deng, W.; Goldys, E.M. X-ray radiation-induced and targeted photodynamic therapy with folic acidconjugated biodegradable nanoconstructs. Int. J. Nanomed. 2018, 13, 3553-3570. [CrossRef]

198. Wang, H.; Lv, B.; Tang, Z.; Zhang, M.; Ge, W.; Liu, Y.; He, X.; Zhao, K.; Zheng, X.; He, M.; et al. Scintillator-Based Nanohybrids with Sacrificial Electron Prodrug for Enhanced X-ray-Induced Photodynamic Therapy. Nano Lett. 2018, 18, 5768-5774. [CrossRef]

199. Park, W.; Cho, S.; Kang, D.; Han, J.H.; Park, J.H.; Lee, B.; Lee, J.; Kim, D.H. Tumor Microenvironment Targeting Nano-Bio Emulsion for Synergistic Combinational X-Ray PDT with Oncolytic Bacteria Therap. Adv. Healthc. Mater. 2020, 9, e1901812. [CrossRef]

200. McHale, A.P.; Callan, J.F.; Nomikou, N.; Fowley, C.; Callan, B. Sonodynamic Therapy: Concept, Mechanism and Application to Cancer Treatment. Adv. Exp. Med. Biol. 2016, 880, 429-450.

201. Ashush, H.; Rozenszajn, L.A.; Blass, M.; Barda-Saad, M.; Azimov, D.; Radnay, J.; Zipori, D.; Rosenschein, U. Apoptosis induction of human myeloid leukemic cells by ultrasound exposure. Cancer Res. 2000, 60, 1014-1020.

202. Umemura, S.; Yumita, N.; Nishigaki, R.; Umemura, K. Mechanism of cell damage by ultrasound in combination with hematoporphyrin. Jpn. J. Cancer Res. 1990, 81, 962-966. [CrossRef]

203. Ma, A.; Chen, H.; Cui, Y.; Luo, Z.; Liang, R.; Wu, Z.; Chen, Z.; Yin, T.; Ni, J.; Zheng, M.; et al. Metalloporphyrin Complex-Based Nanosonosensitizers for Deep-Tissue Tumor Theranostics by Noninvasive Sonodynamic Therapy. Small 2019, 15, e1804028. [CrossRef] [PubMed]

204. Lu, Y.G.; Wang, Y.Y.; Yang, Y.D.; Zhang, X.C.; Gao, Y.; Yang, Y.; Zhang, J.B.; Li, G.L. Efficacy of topical ALA-PDT combined with excision in the treatment of skin malignant tumor. Photodiagn. Photodyn. Ther. 2014, 11, 122-126. [CrossRef] 
205. Yano, T.; Muto, M.; Minashi, K.; Iwasaki, J.; Kojima, T.; Fuse, N.; Doi, T.; Kaneko, K.; Ohtsu, A. Photodynamic therapy as salvage treatment for local failure after chemoradiotherapy in patients with esophageal squamous cell carcinoma: A phase II study. Int. J. Cancer 2012, 131, 1228-1234. [CrossRef] [PubMed]

206. Li, X.Y.; Tan, L.C.; Dong, L.W.; Zhang, W.Q.; Shen, X.X.; Lu, X.; Zheng, H.; Lu, Y.G. Susceptibility and Resistance Mechanisms During Photodynamic Therapy of Melanoma. Front. Oncol. 2020, 10, 597. [CrossRef]

207. McEwan, C.; Nesbitt, H.; Nicholas, D.; Kavanagh, O.N.; McKenna, K.; Loan, P.; Jack, I.G.; McHale, A.P.; Callan, J.F. Comparing the efficacy of photodynamic and sonodynamic therapy in non-melanoma and melanoma skin cancer. Bioorg. Med. Chem. 2016, 24, 3023-3028. [CrossRef]

208. An, Y.W.; Liu, H.Q.; Zhou, Z.Q.; Wang, J.C.; Jiang, G.Y.; Li, Z.W.; Wang, F.; Jin, H.T. Sinoporphyrin sodium is a promising sensitizer for photodynamic and sonodynamic therapy in glioma. Oncol. Rep. 2020, 44, 1596-1604. [CrossRef] [PubMed]

209. Xiong, W.; Wang, P.; Hu, J.; Jia, Y.; Wu, L.; Chen, X.; Liu, Q.; Wang, X. A new sensitizer DVDMS combined with multiple focused ultrasound treatments: An effective antitumor strategy. Sci. Rep. 2015, 5, 17485. [CrossRef]

210. Sadanala, K.C.; Chaturvedi, P.K.; Seo, Y.M.; Kim, J.M.; Jo, Y.S.; Lee, Y.K.; Ahn, W.S. Sono-photodynamic combination therapy: A review on sensitizers. Anticancer Res. 2014, 34, 4657-4664.

211. Chen, H.J.; Zhou, X.B.; Wang, A.L.; Zheng, B.Y.; Yeh, C.K.; Huang, J.D. Synthesis and biological characterization of novel rose bengal derivatives with improved amphiphilicity for sono-photodynamic therapy. Eur. J. Med. Chem. 2018, 145, 86-95. [CrossRef]

212. Sun, D.; Zhang, Z.; Chen, M.; Zhang, Y.; Amagat, J.; Kang, S.; Zheng, Y.; Hu, B.; Chen, M. Co-Immobilization of Ce6 Sono/Photosensitizer and Protonated Graphitic Carbon Nitride on PCL/Gelation Fibrous Scaffolds for Combined SonoPhotodynamic Cancer Therapy. ACS Appl. Mater. Interfaces 2020, 12, 40728-40739. [CrossRef]

213. Zhu, J.; Wang, Y.; Yang, P.; Liu, Q.; Hu, J.; Yang, W.; Liu, P.; He, F.; Bai, Y.; Gai, S.; et al. GPC3-targeted and curcumin-loaded phospholipid microbubbles for sono-photodynamic therapy in liver cancer cells. Colloids Surf. B Biointerfaces 2021, 197, 111358. [CrossRef] [PubMed]

214. Zhu, J.X.; Zhu, W.T.; Hu, J.H.; Yang, W.; Liu, P.; Liu, Q.H.; Bai, Y.X.; Xie, R. Curcumin-Loaded Poly(L-lactide-co-glycolide) Microbubble-Mediated Sono-photodynamic Therapy in Liver Cancer Cells. Ultrasound Med. Biol. 2020, 46, 2030-2043. [CrossRef]

215. Miyoshi, N.; Kundu, S.K.; Tuziuti, T.; Yasui, K.; Shimada, I.; Ito, Y. Combination of Sonodynamic and Photodynamic Therapy against Cancer Would Be Effective through Using a Regulated Size of Nanoparticles. Nanosci. Nanoeng. 2016, 4, 1-11. [CrossRef]

216. Li, L.; Rashidi, L.H.; Yao, M.; Ma, L.; Chen, L.; Zhang, J.; Zhang, Y.; Chen, W. CuS nanoagents for photodynamic and photothermal therapies: Phenomena and possible mechanisms. Photodiagn. Photodyn. Ther. 2017, 19, 5-14. [CrossRef]

217. Curcio, A.; Silva, A.K.A.; Cabana, S.; Espinosa, A.; Baptiste, B.; Menguy, N.; Wilhelm, C.; Abou-Hassan, A. Iron Oxide Nanoflowers @ CuS Hybrids for Cancer Tri-Therapy: Interplay of Photothermal Therapy, Magnetic Hyperthermia and Photodynamic Therapy. Theranostics 2019, 9, 1288-1302. [CrossRef]

218. Luo, L.; Sun, W.; Feng, Y.; Qin, R.; Zhang, J.; Ding, D.; Shi, T.; Liu, X.; Chen, X.; Chen, H. Conjugation of a Scintillator Complex and Gold Nanorods for Dual-Modal Image-Guided Photothermal and X-ray-Induced Photodynamic Therapy of Tumors. ACS Appl. Mater. Interfaces 2020, 12, 12591-12599. [CrossRef] [PubMed]

219. Kodumudi, K.N.; Woan, K.; Gilvary, D.L.; Sahakian, E.; Wei, S.; Djeu, J.Y. A novel chemoimmunomodulating property of docetaxel: Suppression of myeloid-derived suppressor cells in tumor bearers. Clin. Cancer Res. 2010, 16, 4583-4594. [CrossRef] [PubMed]

220. Chen, L.; Zhou, L.; Wang, C.; Han, Y.; Lu, Y.; Liu, J.; Hu, X.; Yao, T.; Lin, Y.; Liang, S.; et al. Tumor-Targeted Drug and CpG Delivery System for Phototherapy and Docetaxel-Enhanced Immunotherapy with Polarization toward M1-Type Macrophages on Triple Negative Breast Cancers. Adv. Mater. 2019, 31, e1904997. [CrossRef]

221. Yang, J.C.; Shang, Y.; Li, Y.H.; Cui, Y.; Yin, X.B. An "all-in-one" antitumor and anti-recurrence/metastasis nanomedicine with multi-drug co-loading and burst drug release for multi-modality therapy. Chem. Sci. 2018, 9, 7210-7217. [CrossRef]

222. Zhang, Y.; Wan, Y.; Chen, Y.; Blum, N.T.; Lin, J.; Huang, P. Ultrasound-Enhanced Chemo-Photodynamic Combination Therapy by Using Albumin "Nanoglue"-Based Nanotheranostics. ACS Nano 2020, 14, 5560-5569. [CrossRef]

223. Feng, L.; Gai, S.; He, F.; Dai, Y.; Zhong, C.; Yang, P.; Lin, J. Multifunctional mesoporous $\mathrm{ZrO}_{2}$ encapsulated upconversion nanoparticles for mild NIR light activated synergistic cancer therapy. Biomaterials 2017, 147, 39-52. [CrossRef]

224. Hou, L.; Shan, X.; Hao, L.; Feng, Q.; Zhang, Z. Copper sulfide nanoparticle-based localized drug delivery system as an effective cancer synergistic treatment and theranostic platform. Acta Biomater. 2017, 54, 307-320. [CrossRef]

225. Li, Q.; Sun, L.; Hou, M.; Chen, Q.; Yang, R.; Zhang, L.; Xu, Z.; Kang, Y.; Xue, P. Phase-Change Material Packaged within Hollow Copper Sulfide Nanoparticles Carrying Doxorubicin and Chlorin e6 for Fluorescence-Guided Trimodal Therapy of Cancer. ACS Appl. Mater. Interfaces 2019, 11, 417-429. [CrossRef]

226. Xu, X.; Han, C.; Zhang, C.; Yan, D.; Ren, C.; Kong, L. Intelligent phototriggered nanoparticles induce a domino effect for multimodal tumor therapy. Theranostics 2021, 11, 6477-6490. [CrossRef] [PubMed]

227. Han, R.; Tang, K.; Hou, Y.; Yu, J.; Wang, C.; Wang, Y. Ultralow-intensity near infrared light synchronously activated collaborative chemo/photothermal/photodynamic therapy. Biomater. Sci. 2020, 8, 607-618. [CrossRef] [PubMed]

228. Xu, W.; Qian, J.; Hou, G.; Wang, Y.; Wang, J.; Sun, T.; Ji, L.; Suo, A.; Yao, Y. PEGylated hydrazided gold nanorods for pH-triggered chemo/photodynamic/photothermal triple therapy of breast cancer. Acta Biomater. 2018, 82, 171-183. [CrossRef] 
229. Wen, J.; Yang, K.; Ding, X.; Li, H.; Xu, Y.; Liu, F.; Sun, S. In Situ Formation of Homogeneous Tellurium Nanodots in PaclitaxelLoaded MgAl Layered Double Hydroxide Gated Mesoporous Silica Nanoparticles for Synergistic Chemo/PDT/PTT Trimode Combinatorial Therapy. Inorg. Chem. 2019, 58, 2987-2996. [CrossRef]

230. Obaid, G.; Broekgaarden, M.; Bulin, A.L.; Huang, H.C.; Kuriakose, J.; Liu, J.; Hasan, T. Photonanomedicine: A convergence of photodynamic therapy and nanotechnology. Nanoscale 2016, 8, 12471-12503. [CrossRef]

231. Mroz, P.; Hamblin, M.R. The immunosuppressive side of PDT. Photochem. Photobiol. Sci. 2011, 10, 751-758. [CrossRef] [PubMed] 